Discussion

Papers

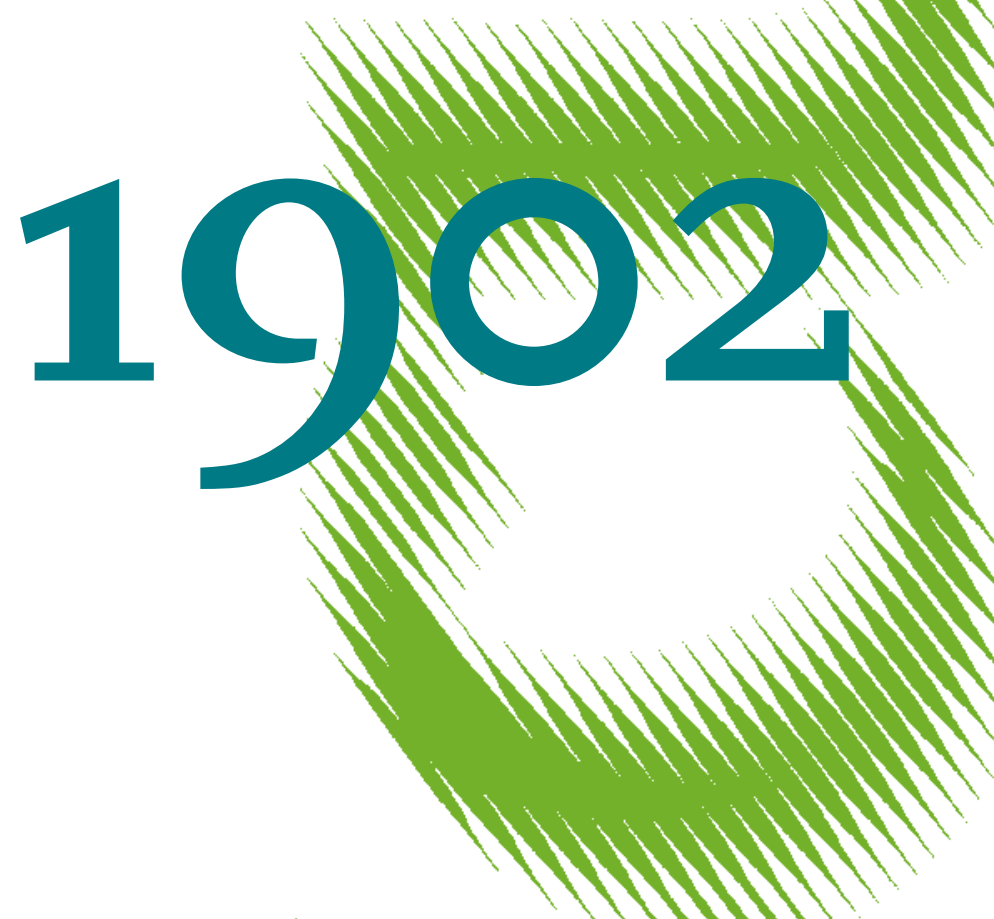

Health of Elderly Parents, Their Children's Labor Supply, and the Role of Migrant Care Workers 
Opinions expressed in this paper are those of the author(s) and do not necessarily reflect views of the institute.

IMPRESSUM

(C) DIW Berlin, 2020

DIW Berlin

German Institute for Economic Research

Mohrenstr. 58

10117 Berlin

Tel. +49 (30) $89789-0$

Fax +49 (30) $89789-200$

http://www.diw.de

ISSN electronic edition 1619-4535

Papers can be downloaded free of charge from the DIW Berlin website:

http://www.diw.de/discussionpapers

Discussion Papers of DIW Berlin are indexed in RePEc and SSRN:

http://ideas.repec.org/s/diw/diwwpp.html

http://www.ssrn.com/link/DIW-Berlin-German-Inst-Econ-Res.html 


\title{
Health of Elderly Parents, their Children's Labor Supply, and the Role of Migrant Care Workers*
}

\author{
Wolfgang Frimmel ${ }^{\mathrm{a}, \mathrm{b}}$, Martin Halla ${ }^{\mathrm{a}, \mathrm{b}, \mathrm{c}, \mathrm{d}}$, Jörg Paetzold ${ }^{\mathrm{e}, \mathrm{f}}$, Julia \\ Schmiederg,c,h \\ ${ }^{a} J K U$, Johannes Kepler University Linz \\ ${ }^{\mathrm{b}}$ Christian Doppler Laboratory Aging, Health and the Labor Market, Linz \\ ${ }^{\mathrm{c}} I Z A$, Institute for the Study of Labor, Bonn \\ ${ }^{\mathrm{d}} G \ddot{O} G$, Austrian Public Health Institute, Vienna \\ ${ }^{\mathrm{e}}$ University of Salzburg \\ ${ }^{\mathrm{f}} \mathrm{NoCeT}$, NHH Bergen \\ ${ }^{\mathrm{g}}$ DIW, German Institute for Economic Research, Berlin \\ ${ }^{\mathrm{h}}$ Berlin School of Economics
}

October 1, 2020

\begin{abstract}
We estimate the impact of parental health on adult children's labor market outcomes. We focus on health shocks which increase care dependency abruptly. Our estimation strategy exploits the variation in the timing of shocks across treated families. Empirical results based on Austrian administrative data show a significant negative impact on labor market activities of children. This effect is more pronounced for daughters and for children who live close to their parents. Further analyses suggest informal caregiving as the most likely mechanism. The effect is muted after a liberalization of the formal care market, which sharply increased the supply of foreign care workers.
\end{abstract}

JEL Classification: J14, J22, I11, I18, R23.

Keywords: Informal care, formal care, aging, health, labor supply, labor migration.

*Corresponding author: Martin Halla, Johannes Kepler University of Linz, Department of Economics, Altenbergerstraße 69, 4040 Linz, Austria; email: martin.halla@jku.at. For helpful discussions and comments we would like to thank Maximilian Bach, Christian Dustmann, Ludovica Giua, Peter Haan, Enkelejda Havari, Thorben Korfhage, Vincent Pohl, Andrea Weber, Rudolf Winter-Ebmer, and seminar participants at the NOeG Annual Meeting 2019 in Graz, the $11^{\text {th }}$ Norwegian German Seminar on Public Economics at CESifo Munich, the WU Vienna, the DIW Berlin, the ifo Center for the Economics of Education, the Competence Centre on Microeconomic Evaluation at the Joint Research Center of the European Commission in Ispra, the Berlin Network of Labor Market Research, and the Mannheim Applied Seminar. The usual disclaimer applies. Financial support from the Christian Doppler Laboratory "Aging, Health and the Labor Market" and the Deutsche Forschungsgemeinschaft through CRC TRR 190 (project number 280092119) is gratefully acknowledged. 


\section{Introduction}

Improvements in health care and declines in fertility have led to a global trend of rising longevity and an increasing share of older people. This trend is most pronounced in highincome countries, where high dependency ratios put pressure on public pension funds. A related key challenge of an aging population is the need for long-term care (LTC). In almost all OCED member states, budgets for LTC have expanded. Between 2005 and 2015 , the average annual growth rate of public spending on LTC was 4.6 percent OECD, 2017). Spending by government and compulsory insurance schemes on LTC has increased more rapidly than health care expenditure over this period. However, not only public budgets are strongly affected by the increasing need for elderly care, but also households who provide a significant share of LTC informally.

We are interested in the consequences of deteriorating parental health for the labor market outcomes and well-being of adult children. Providing informal care is not only time-consuming, but can also be psychologically and physiologically challenging (Bom et al., 2019). Thus, parents' health may affect their children's allocation of time (Pezzin and Schone, 1997, 1999) and their own health. The identification of causal effects is challenging in this context. First, it is difficult to construct an adequate counterfactual scenario since health conditions are usually endogenous and often change gradually. Second, rich longitudinal individual-level data on health and labor market outcomes for both parents and their children are needed to evaluate mid- and long-run effects. Third, objective measures for parental care dependency are necessary to obtain informative estimates. Survey data on LTC obligations of family members are usually not suited to study long-run effects and may often be subject to justification bias (Black et al., 2017).

We tackle these challenges by leveraging high-quality administrative data from Austria. We have access to register-based information on health-care utilization, degree of care dependency, and labor market outcomes from 1998 to 2017. To identify causal effects we focus on two types of sudden and unexpected health shocks, namely strokes and heart attacks (myocardial infarction).1 $\mathrm{H}^{1}$ We employ a quasi-experimental event study design that is based on the comparison of children whose parents all suffer the same health shock but at different points in time. Our identifying assumption is that the exact timing of the health shock is as good as random. Comparable identification strategies are used in Druedahl and Martinello (2016); Fadlon and Nielsen (2019, 2020).

We show that both strokes and heart attacks are severe health shocks, with permanent consequences for parental health-care spending and labor productivity. One important difference between these two conditions is their differential impact on care dependency. We find the effect of a stroke on care dependency to be ten times larger than that of a

\footnotetext{
${ }^{1}$ Strokes and heart attacks are commonly studied as sudden and severe health events that are unlikely to be anticipated (see, e.g., Chandra and Staiger, 2007; Doyle, 2011; Druedahl and Martinello, 2016; Dobkin et al., 2018; Fadlon and Nielsen, 2019, 2020).
} 
heart attack. Our estimated effects of parental health shocks on adult children's labor market participation and earnings reflect this gradient. Our baseline estimates show significant negative effects of parental strokes on their adult children's employment and labor earnings. We observe a statistically significant drop of around 2.5 percentage points (3.5 percent) in children's employment one year after the parental stroke with a slight recovery thereafter. Children's labor earnings decrease permanently due to the parental stroke. One year after the stroke, earnings are statistically significant 3.9 percent lower relative to their pre-shock level. Three years after the stroke, the negative effect builds up to 5.7 percent. In contrast, we find heart attacks to not affect children's labor market outcomes. For both types of parental health shocks we do not observe negative effects on the overall or mental health of children. This suggests that the negative effect of a parental stroke on the labor market outcomes of children is not explained by worsening health and, in particular increased mental stress, of their children.

There are two remaining mechanisms through which a parental health shock could affect adult children's own labor market activity: (i) Children provide informal care to their parent. This would lead to a decrease in labor supply in order to free up time. (ii) Or, children transfer money to their parents to compensate for the earnings loss associated with the health shock. This would cause an increase in their own labor supply. If both mechanisms are present, our estimates would present the mix of two opposing forces: A reduction in labor supply in order to transfer time, and an increase in labor supply to transfer money. Fortunately, we have two sub-samples available in which we can shut-off the "care shock" and the "income shock", respectively. First, we repeat our analysis for the sub-sample of families whose parent died from the stroke. Fatal shocks do not lead to care requirements (no care shock). We do not observe any effect on children's labor market outcomes for this type of shock. Second, we repeat our analysis for the sub-sample of children whose parents had been already retired before the stroke. For these parents, the stroke has no impact on earnings (no income shock). We obtain estimated treatment effects of similar magnitude as compared to our baseline estimates. These two results are in line with the explanation based on the provision of informal care driving the negative labor market effects of adult children. Further support for this interpretation comes from our results on treatment effect heterogeneity. First, the negative labor market effect is only observed for strokes, but not for heart attacks. The main difference between these two conditions is that the impact on care dependency is a magnitude larger after a stroke than after a heart attack. Second, we find stronger effects for children who live close to their parents at the time of the stroke. Geographical distance determines the opportunity cost of providing time, but not money. All this evidence suggests that income compensation through adult children plays at most a minor role in our population and that the provision of informal care is the relevant mechanism.

There is a sharp gender gradient in the informal provision of care after a parental 
stroke: We find the labor market response of children to differ substantially by their gender. One year after the parental stroke, daughters are statistically significant 4.4 percentage points (or 6.7 percent) less likely to be employed. While this employment differential dissipates over time, we find that the earnings losses of daughters remain relatively constant throughout the post-shock period. Three years after the stroke, daughters earn 9.1 percent less relative to their earnings before the shock. For sons, we observe much smaller negative effects, which are not statistically distinguishable from zero. The gender gradient in our results demonstrates how gender inequality in unpaid informal care work contributes to gender inequality in the paid labor market. This mirrors the literature on gender inequality in labor market outcomes resulting from important life events in the private domain, for example from the arrival of children (Kleven, Landais and Sogaard, 2019, Kleven, Landais, Posch, Steinhauer and Zweimüller, 2019).

Our results contribute to the existing literature on the impact of negative health shocks on labor market outcomes. Most of these studies focus on the effects of a health shock on own (i.e., of the affected person) labor market outcomes (see, e.g., Halla and Zweimüller, 2013; Gupta et al., 2015; Dobkin et al., 2018). Fewer studies look at the effects of health shocks on other family members' labor market outcomes with a majority focusing on spouses: ${ }^{2}$ The impact on the labor supply of adult children is much less understood. In order to observe the informal provision of care, studies in this literature usually employs survey data on self-reported care obligations and parental health conditions $\mathrm{S}^{3}$ While this provides a viable indicator for informal caregiving (though potentially not bias-free, see Black et al. (2017)), it is often challenging to exploit quasi-experimental variation using this data. To the best of our knowledge, only two (design-based) studies employ administrative data and exogenous variation to examine the impact of parental health shocks on their adult children. The evidence is mixed. Fevang et al. (2012) find in Norwegian data that children of terminally ill parents reduce their labor supply temporarily. However, given that many of the parents in their sample have suffered from foreseeable terminal illnesses, it is difficult to rule out anticipatory effects (e. g. stemming from gifts or forthcoming bequests). In contrast to their results, Rellstab et al. (2020) find in Dutch data no effect of an unexpected parental hospitalization on their children's labor market outcomes. Potential explanations for this zero-result are the unclear effect of these hospitalizations on care dependency, and/or the extensive public coverage of formal long-term care in

\footnotetext{
${ }^{2}$ In this context, effects depend on the severity of the health shock. Specifically, for non-fatal shocks, studies have found a reduction in employment and labor supply of the spouse (see, for e. g., GarciaGómez et al. 2013, Jeon and Pohl, 2017, Fadlon and Nielsen, 2020). When looking at fatal shocks instead, spousal labor supply sometimes even increases to compensate for the income losses caused by the death of a partner (Fadlon and Nielsen, 2020). The size of the effect tends to vary across sexes and how well the institutional system insures against income losses.

${ }^{3}$ The vast majority of these papers find a negative effect of informal caregiving on employment and/or wages (see, for e.g., Heitmueller, 2007; Bolin et al., 2008, Carmichael et al., 2010, Ciani, 2012, Van Houtven et al., 2013, Crespo and Mira, 2014, Bauer and Sousa-Poza, 2015, Heger and Korfhage, 2020).
} 


\section{Netherlands, 4}

Most studies in this literature do not have access to direct and objective measures for the severity of the sudden health deterioration of the affected parent. In our study, we use a measure of the severity of the shock by exploiting information on parental medical conditions. More importantly, we also employ administrative data on parental care dependency, stemming from official assessments by independent physicians. To the best of our knowledge, this is the first paper employing a measure of care dependency from administrative sources for an entire population.

In the second part of the paper, we go one step further and contribute to the question of how public policies could address the negative labor market effects stemming from informal caregiving. In 2007, the Austrian government enacted a reform that liberalized formal care work at private homes and exempted migrant care workers from pre-existing labor market restrictions for citizens of Central and Eastern EU member countries (Österle and Bauer, 2016). We show that this reform led to a very large positive supply shock of formal care provided by migrant care workers. To exploit this policy change we implement a triple-difference (DDD) strategy using shocks before and after the reform and children whose parents suffer from a heart attack as a control group. This strategy is based on the idea that children whose parents suffer from a heart attack are largely unaffected by the care reform because their parents do not develop caring needs in any comparable way than those who suffer from a stroke. At the same time, children with a parental heart attack should be subject to the same general changes in the labor market over time. Our results show significantly positive and economically relevant labor market effects from the reform, suggesting that the care reform with its large increase in the availability of formal care helped children to avoid the negative impact of a parental stroke $5^{5}$ In sum, this result indicates that migrant care workers act as substitutes for adult children's informal care work, a factor that can be influenced by migration policies. To the best of our knowledge, our paper is the first empirical study that attempts to causally establish the labor supply effects of loosening restrictions regarding foreign LTC workers. ${ }^{6}$

\footnotetext{
${ }^{4}$ Rellstab et al. (2020) use 11 severe health shocks (including cancer, heart attacks, and strokes), but do not observe subsequent care dependency of the patients. Using our data, we can show that health shocks such as heart attacks have only a negligible impact on care dependency. In contrast, we find strokes to increase care dependency substantially. Only 12 percent of the sample used by Rellstab et al. (2020) concern strokes, which may offer a potential explanation of why they find no effect on adult children. Furthermore, the authors argue that the comprehensive LTC institutions in the Netherlands are likely to explain their zero result. The Netherlands has an extensive public coverage of formal long-term care and one of the highest LTC expenditure per capita in the OECD (OECD, 2017). In contrast, Austria with its balance between informal and formal care arrangements is much more similar to the LTC provisions of many other OECD countries.

${ }^{5}$ A related study by Løken et al. (2017) looks at the expansion of public spending on the home care provision for the elderly and finds that adult children do not change their employment decision, but they reduce the number of insured sickness absences at work as a response to the reform.

${ }^{6}$ Previous literature has documented how increases in the supply of low-skilled immigrants have led native women to decrease the time spent in household work and increase time devoted to market work (e.g., Cortés and Tessada, 2011; Farré et al., 2011), as well as have helped reduce the gender gap in the
} 
This mitigating effect of the positive supply shock of formal care workers has to be interpreted against the background of prevailing social norms. Caring for sick parents is an important duty in many cultures. Austria is a typical example for a conservative continental European welfare state, characterized by traditional family values and familybased assistance dynamics (Akerlof and Kranton, 2000; Esping-Andersen, 1999). These traditional norms and values also include elderly care. Figure 1 shows the opinion of individuals regarding the question "Who should take care of an elderly parent?" for several countries. In Austria, as well as in other more family-based welfare states such as Germany, around 50 percent of all respondents believe that it is the role of adult children to take care of their elderly parents. In Scandinavian and Benelux countries, only around 20 percent of all survey respondents agree with this statement. Our estimation results show that the degree of substitutability between informal care provided by children and formal care providers is high enough to provide scope for policy interventions on the formal care market, even in the context of strong family-based social norms.7

The remainder of this paper is organized as follows. Section 2 describes the institutional background in Austria and the data used for our analysis. Section 3 outlines our research design, and spells out the identification assumptions. Section 4 presents the estimated effect of a health shock on own health and labor productivity. Section 5 presents our estimates of main interest, the impact of a parental health shock on adult children's labor market outcomes. Section 6 provides evidence to uncover the causal mechanism underlying our baseline estimates. Section 7 demonstrates the robustness of our baseline estimates. Section 8 shows how treatment effects are affected by a liberalization of formal care work, which has increased the supply of migrant care workers. Section 9 concludes the paper.

\section{Institutional background and data sources}

\subsection{Institutional setting}

The Austrian LTC system rests on three main pillars. First, there is a LTC allowance program (Pflegegeld). Second, there is a publicly coordinated but decentralized market for formal LTC. Third, there is informal care provided by families. In 2018, LTC was mainly provided in five different settings: exclusively informal by families $(42 \%)$, in formal home care $(32 \%)$, in residential care $(16 \%)$, in 24 -hour home care by privately paid assistants

propensity to work long hours or increased the relative earnings of women in occupations that disproportionately reward overwork (Cortés and Pan, 2019). More specifically, Cortés and Pan (2013) show in the case of childcare how a migration policy change regarding foreign household helpers increased labor force participation of young mothers.

${ }^{7}$ Exploiting (regional) variation in social norms (for example, approximated by election results) to examine whether the effect of the 2007 reform is muted in more conservative areas is complicated due to the lack of exogenous variation in social norms, which often correlate with other confounding factors. 
$(5 \%)$, and in day care $(2 \%)$ (Famira-Mühlberger, 2020).

\subsubsection{LTC allowance program}

The cornerstone of the Austrian LTC policy is a comprehensive care allowance scheme (Pflegegeld). This is a legal entitlement for every citizen, who is in need of care in order to provide funding for care-related expenses. It grants cash on a needs - but not means tested basis (Firgo et al., 2020). Eligibility assessment is executed by SHI-accredited public doctors and based on individual requirements for personal services, assistance, and care (Riedel and Kraus, 2010). The law defines seven levels of care need and corresponding monthly cash benefits of the allowance range from $€ 150.3$ at level one to $€ 1,688.9$ at level seven (for 2016). Level one is granted when care requirements exceed 65 hours per month, and level seven corresponds to more than 180 hours of needed care per month (see Table A.1) 8 We will use data on care allowance receipt to observe parental care dependency.

Overall, 5.3\% of all Austrians received this care allowance in 2016. The allowance is a cash (and not in-kind) benefit, which can be used freely. Thus, it can be used for informal and formal care arrangements alike. While the care allowance certainly helps families to cover certain expenses and to pay for formal care arrangements, the collected benefits are often insufficient to afford full formal care provision (Riedel and Kraus, 2010). Thus, co-financing as well as informal care provision by family members is common. This had been amplified (until 2018) by a legal system of recourse to the assets of people in inpatient LTC and of their relatives (so-called "Pflegeregress"). In sum, the overall legal framework encourages (at least partly) the informal provision of care by family members and mirrors preferences of the population about who should take care of an elderly person (see Figure 1).

\subsubsection{Formal care}

The second main element consists of different formal care settings, which are the responsibility of the nine federal provinces. There are two main types: Institutional and home-based care. The former is mainly provided by provinces and municipalities, or by religious and other nonprofit organizations. These services usually include care in residential homes, nursing homes, day-care centers, and night-care centers. Home-based services are predominantly provided by nonprofit organizations. They include, among others, home (nursing) care, mobile therapeutic services, home-delivered meals, transport, house cleaning and laundry, and help on weekends. In 2007, a policy reform enabled private households to hire care workers. This policy reform aimed to increase the availability and affordability of formal care in a home-based setting called "24-hour care" provision.

\footnotetext{
${ }^{8}$ Additionally to the care requirement in hours, levels five to seven have additional criteria to be met, e.g., no goal-directed movements of the person's four extremities or equivalent conditions.
} 
A keystone of this reform was the exemption of foreign care workers from the existing labor market restrictions for citizens of Central and Eastern EU member countries. This resulted in a large inflow of foreign care workers to Austria. Today, "24-hour care" is almost exclusively provided by self-employed live-in migrant care workers from Slovakia and Romania (Österle and Bauer, 2016). In Section 8, we exploit this policy change to examine whether this expansion of the formal care market in Austria helped adult children to mitigate the negative effects of a parental health shock.

\subsubsection{Informal care}

The Austrian Time Use Survey (Zeitverwendungserhebung) is the best available data source to assess the extent of informal care. The most recent survey was conducted between March 2008 and April 2009 (Statistik Austria, 2009). It shows that 2.23 percent of the population provides informal care for the elderly. The average caregiver provides about 9.4 hours per week. The strongest predictor for informal care supply is the age of the caregiver. The likelihood of provision and the hours supplied rise both with his or her age. The participation rates vary across sexes, with 3.10 percent among women and 1.18 among men. Thus, about 72 percent of all caregivers are female. At the intensive margin, the gender divide is less pronounced (women: 9.7 hours, men: 8.7 hours). Finally, there is also variation across educational attainment groups. Individuals with compulsory education are more than twice as likely to provide informal care as compared to those with tertiary education (3.20 versus 1.36 percent). All these patterns are also present in a regression-based analysis (see Appendix Table A.2). Another survey among Austrians with caring needs conducted in 2014 found that two-thirds of the respondents received care from close relatives (Famira-Mühlberger, 2017). Around 30 percent of the care was provided by the spouse, 24 percent by the daughter, and 12 percent by the son.

\subsection{Administrative data sources}

To study the effect of the health of elderly parents on their children's labor supply, we use several data sets. We combine the Upper Austrian Health Insurance Fund (UAHIF) database with the Austrian Social Security Database (ASSD) as well as with data from the Austrian Ministry of Finance. The UAHIF is the main statutory health insurance provider in the federal state of Upper Austria. ${ }^{9}$ Around $75 \%$ of the Upper Austrian population is insured via the UAHIF. The remaining $25 \%$ is comprised of self-employed individuals, farmers, civil servants, and workers in the railway and mining industries, which are insured with other institutions. Importantly, pensioners continue to be insured with the UAHIF when they have been insured prior to their retirement. The UAHIF

\footnotetext{
${ }^{9}$ Unfortunately, the health insurance data is only available from Upper Austria. Upper Austria has around 1.5 million inhabitants, which makes it the third-largest federal state of Austria.
} 
database comprises individual-level information on the universe of health care service utilization in the inpatient and outpatient sector. The ASSD provides us with information on labor market behavior, pension and, unemployment spells as well as a range of demographic characteristics. Finally, data from the Austrian Ministry of Finance allows identifying all care allowance recipients of Upper Austria on an annual basis. Overall, the data we use is available from 1998 to 2017,10

\section{$3 \quad$ Research design}

\subsection{Empirical strategy}

The goal of our analysis is to estimate the dynamic causal effect of parental health on the family members' labor market and health outcomes, with a focus on adult children. The identification of causal effects is challenging in this setting: The health status of a person might be anticipated and endogenous, both with respect to his or her own, and with respect to other family members' outcomes. First, if health is gradually deteriorating, both affected parents and their children may anticipate future care requirements and start adjusting their labor market behavior, as well as their human capital formation already before a certain health deterioration takes place. We tackle this issue by exploiting sudden health shocks. We focus on strokes and heart attacks experienced by an individual for the first time. Second, parents' health status might be related to unobservable characteristics that potentially correlate both with their own and their family members' outcomes. To address this issue, our identification builds on a homogeneous group of families, who all suffer from the same parental health shock, but at different points in time. Thus, they differ only in the timing of this sudden deterioration of parental health. In other words, our research design exploits the randomness in the timing of the parental health shock, which is similar to that used by Druedahl and Martinello (2016); Fadlon and Nielsen (2020, 2019).

We employ the following event-study model with cohort-specific time and individual fixed effects:

$$
O_{i, t}=\kappa_{<-12} I\left\{t-\tau_{i}<-12\right\}+\sum_{\substack{k=-12 \\ k \neq-4}}^{12} \kappa_{k} \cdot I\left\{t-\tau_{i}=k\right\}+\lambda_{c, t}+\psi_{i}+\varepsilon_{i, t}
$$

where $O_{i, t}$ denotes the outcome of individual $i$ observed in quarter $t$. We separately estimate the model for parents and children. A parent has an own health shock whereas a child experiences a health shock of his or her parent at time $\tau_{i}$. The number of quarters

\footnotetext{
${ }^{10}$ Please note that some of the data is available only for a shorter period. For instance, the data on care allowance receipt is only available until 2012, and some variables from the health care records start in 2005 .
} 
relative to the quarter of the shock is denoted by $k=t-\tau_{i}$ and, hence, $I\left\{t-\tau_{i}=k\right\}$ are indicators for time relative to the quarter of the shock. We omit the event time dummy at $k=-4$, standardizing its coefficient to zero. $\lambda_{c, t}$ and $\psi_{i}$ are quarter-by-cohort and individual fixed effects, respectively. By cohort, we refer to the birth year of individual $i$. We report robust standard errors clustered at the individual level.

The parameters of interest are $\kappa_{k}$, which are the period $k$-effects relative to the reference period four quarters before the shock. Parameters for $k>0$ refer to effects after the shock. In this type of event-study model it is important to assure that the dynamic treatment effects are separately identified from secular time fixed effects. In a setup with no never-treated units as ours, i.e. all individuals experience a parental health shock at some point, dynamic effects are only identified up to a linear trend (Borusyak and Jaravel, 2017). Restricting the effect window by the binning of endpoints introduces restrictions to avoid underidentification. In our model, we restrict the treatment effects to be constant before twelve quarters prior to the shock with the binned treatment indicator $I\left\{t-\tau_{i}<-12\right\}$. Intuitively, binning assigns the individual-quarter observations outside of the effect window to the control group which pins down the secular time trends (Schmidheiny and Siegloch, 2020).

To interpret the event-study coefficients $\kappa_{k}$ as causal effects of the parental health shock requires the identifying assumption that conditional on cohort-specific time and individual fixed effects the timing of the shock is uncorrelated with the outcome variable. This implies that the outcome would have evolved in a parallel way for individuals in the same cohort that are treated at different points in time in absence of the health shock. Our event-study design allows to examine patterns in outcomes in the quarters up to three years before the shock, which provides a test for the plausibility of our assumption. The quarter-bycohort fixed effects included in our model control non-parametrically for cohort-specific life-cycle and time patterns in the outcome variable. This is important because both parents and children have potentially complex counterfactual life-cycle patterns, i.e. the parental health shock hits them, on average, around the time of retirement and of family formation, respectively.

Our event-study approach uses a varying control group over $k$, the quarters relative to the quarter of the shock (Druedahl and Martinello, 2016). As a robustness check, we implement the approach of Fadlon and Nielsen $(2020,2019)$ that relies on a fixed control group over $k$. More precisely, we compare the outcomes of families who experience a health shock in time $\tau$ with those of families who experience the same shock twelve quarters in the future, i.e. in $\tau+12$. We use the latter group as explicit control group and assign them a placebo shock at time $\tau$. Based on this treatment and control group, we estimate a dynamic difference-in-differences (DD) model. The results from this robustness check are described in Section 7 . 


\subsection{Analysis sample and descriptive statistics}

We construct our sample based on all legitimate children. This guarantees that we have a link between children and both parents. We then restrict our analysis to families in which at least one parent suffers a stroke or heart attack for the first time between 1998 and 2017. These health shocks are identified by WHO's ICD-10 codes (I63 and I21, respectively) available in the UAHIF data. In defining the first shock, we face the limitation that we do not observe health outcomes before 1998. We only consider the event of the first observable shock, and in our main analysis sample we focus on non-fatal shocks ${ }^{11}$ Furthermore, we only include children in our data who are older than 23 years at the time of the shock. This ensures a certain level of attachment to the labor market throughout the time window of our analysis. Thus, our main sample comprises families who experienced a parental health shock, and who include at least one child above age 23 at the time of the stock.

Table 1 provides summary statistics of our sample. It reports average characteristics at four quarters before the respective health shock. In total, we observe 2,763 individuals who experience a stroke, and 3,437 individuals who experience a heart attack for the first time between 1998 and 2017. Parents suffering from a stroke are with an average of 61.1 years somewhat older than those experiencing a heart attack (58.7 years). Around onethird of parents with a stroke and one-quarter of those with a heart attack are female. Around $38 \%$ (51\%) of the parents suffering a stroke (heart attack) are employed and have average earnings, unconditional on being employed, of 2,597 Euro (3,755 Euro) per quarter one year prior to the health shock. 6 (2) percent of all parents hit by a stroke (heart attack) received a care allowance one year prior to the shock.

Their spouses are, on average, around two years younger. Their employment rate is of similar magnitude but their average earnings are lower. Children are around 29 to 30 years old when the parental health shock occurs 12 They are much more attached to the labor market one year prior to the parental health shock compared to their affected parents with employment rates well above $70 \%$ and higher quarterly earnings. In sum, our sample comprises 9,407 children.

\footnotetext{
${ }^{11}$ In our main sample, we define non-fatal shocks as shocks from which the affected parent does not die within a week. We provide a robustness analysis using only families in which the affected parent is alive over the entire time horizon of our analysis (survival $\geq 3$ years) in Section 7 .

${ }^{12}$ Please note that we cannot link parents to children when those are born prior to 1971. This limitation combined with the fact that the UAHIF data is only available after 1998 makes our analysis sample relatively young.
} 


\section{Estimation results: Parents}

\subsection{Parental stroke}

We start by looking at the outcomes of the affected parent around the time of the stroke. Figure 2 depicts the estimated effect of the stroke on various health- and employmentrelated outcomes on a quarterly basis from three years before to after the stroke. As defined above, the effect at event time $k$ is relative to the reference period four quarters before the shock. The figure includes $95 \%$ confidence bands around the event coefficients. Panels (a) to (d) show the estimated effect of the stroke on the number of days in the hospital, total health-care expenses, spending on medical drugs, and care allowance receipt, respectively. We find large and highly significant impacts of the stroke on all of these outcomes. Days spent in the hospital increase by, on average, 14 days and total health expenses rise by around 8,000 Euro per quarter at the time of the shock relative to a pre-shock mean of 0.9 days and 689 Euro per quarter, respectively. The effects remain positive and statistically significant in the subsequent quarters, but are substantially smaller in size. Spending on medical drugs increases permanently by around 70 Euro per quarter due to the stroke. Finally, the share of care allowance recipients increases by 14 percentage points with the stroke and remains high several quarters thereafter. This represents a sharp increase, given that only 6 percent of all parents hit by a stroke received a care allowance one year prior to the shock. It underpins the lasting effect of a stroke on long-term care dependency. Importantly, the patterns observed in Panels (a) to (d) in Figure 2 indicate no significant pre-shock effects on the respective outcome except in the three quarters immediately preceding the shock. This provides support for the assumption that there are no general differences in the underlying trends for individuals who are shocked at different points in time. The only notable exception is within the 2-3 quarters before the shock. Parental health outcomes slightly worsen in this period, as indicated by small increases in hospitalizations and health-related spending. ${ }^{13}$ We also discuss these pre-shock health problems again when presenting our results based on an alternative estimation method (Fadlon and Nielsen, 2020, 2019), which provides a very transparent way to deal with this.

Next, we examine the effect on labor market outcomes of the affected parent around the time of the stroke. Panel (e) and (f) in Figure 2 displays the impact of the stroke on parental employment and quarterly earnings, respectively. We observe significant impacts of the shock on these labor market outcomes. The percentage of affected parents that are in employment drops by around 12 percentage points in the quarters after the shock.

\footnotetext{
${ }^{13}$ A potential explanation for this pattern is a clustering of so-called transient ischemic attacks (TIAs). The medical literature discusses a pattern where strokes can sometimes be preceded by transient ischemic attacks (see, e.g., Johnston et al., 2000). Furthermore, the small uptick in care allowance receipt before the shock is related to the fact that this data is only available annually, which makes a clear assignment to a specific quarter difficult.
} 
The effect is relatively constant throughout the post-period. Given that the employment rate is 38 percent prior to the stroke, this constitutes a reduction in employment by around 30 percent. The negative effect on quarterly earnings is gradually increasing in absolute terms and amounts to a reduction of around 30 percent two years after the stroke relative to the pre-shock earnings. Overall, a stroke severely and persistently affects the labor market outcomes of the parent. Again, the patterns observed in Panels (e) and (f) in Figure 2 show no pre-trends up to three quarters before the shock. The decline in parental employment and labor earnings mirrors the development in health-related outcomes around the time of the stroke.

\subsection{Parental heart attack}

We now turn to the estimated effect of a parental heart attack on parents' health and labor market outcomes (see Figure 3). As in the case of strokes, we find large and significant effects of the heart attack on all outcomes ${ }^{14}$ However, some important differences emerge. For instance, parents with a heart attack experience an increase of an average of eight days spent in the hospital in the quarter of the health shock, which is about half of the effect for a stroke. Spending on prescription drugs is particularly large in the year following the heart attack but drops to a substantially lower level thereafter. Most importantly, parents suffering from a heart attack do not experience such a substantial increase in their care dependency as stroke patients. To be more precise, the share of parents who receive a care allowance increases by 1.4 percentage point due to a heart attack, compared to 14 percentage points due to a stroke. This difference in the need for care suggests that any potential negative consequences on the labor market or health outcomes of children due to caregiving should be much larger after a parental stroke compared to a heart attack.

Panel (e) in Figure 3 shows a significant reduction in the employment rate by around 10 percentage points (20 percent) due to a heart attack. Quarterly earnings decrease substantially as a consequence of a heart attack (see Panel f). The reduction in earnings averages around 20 percent three years after the heart attack relative to the earnings before the shock. In sum, the negative effects on parental labor market outcomes due to a heart attack are similar in absolute but smaller in relative terms compared to the effects due to a stroke.

\footnotetext{
${ }^{14}$ We also see here some increases in the number of days in the hospital and health-care spending in the quarter prior to the shock. This is most likely due to the treatment of angina pectoris, which refers to chest pain or discomfort occurring when the heart muscle does not get as much blood as it needs.
} 


\section{Estimation results: Children}

\subsection{Children after parental stroke}

We now turn to the effect of parental strokes on children's labor market outcomes ${ }^{15}$ Our results in Figure 4 show a significant negative effect of a parental stroke on adult children's employment and labor earnings. In Panel (a), we observe a statistically significant drop of around 2.5 percentage points (or 3.5 percent) in children's employment one year after the parental stroke with a slight recovery thereafter. At the same time, children's labor earnings decrease due to the parental stroke. One year after the shock, quarterly earnings are statistically significant 175 Euro lower (see Panel b). Three years after the shock, the negative effect builds up to 257 Euro. This corresponds to a reduction of 3.9 and 5.7 percent, respectively, relative to the average quarterly earnings prior to the shock ${ }^{16}$

\subsection{Children after parental heart attack}

Next, we turn to the labor market outcomes of children whose parent suffers from a heart attack displayed in Figure 5. In contrast to a parental stroke, we find no statistically significant labor market effects for children after a parental heart attack. As outlined above, the main difference between the two conditions is that the impact on care dependency is a magnitude larger after a stroke than after a heart attack. Thus, the null result following a heart attack is a first piece of evidence pointing to parental care dependency as the causal mechanism underlying the negative impact of a parental stroke on adult children's labor supply.

\section{Mechanism and treatment effect heterogeneity}

To probe further into the mechanism behind the negative labor market response following a stroke, we inspect treatment effect heterogeneity through a series of tests. In principle, there are two main mechanisms through which a parental health shock could affect adult children's labor market outcomes: First, children reduce their labor supply to free up time

\footnotetext{
${ }^{15} \mathrm{We}$ are interested in the effect of a health shock on the labor market outcomes of children. In Appendix Section A.2, we additionally present results for the labor market outcomes of spouses. In line with findings in Fadlon and Nielsen (2020), we find that non-fatal shocks do not affect spousal labor market outcomes.

${ }^{16}$ Table 2 provides the average effect of a parental stroke on children's labor market outcomes over the post period, i.e. over the twelve quarters after the shock. The average employment effect is a reduction by 2 percentage points; the average effect on children's labor earnings is a decrease by 196 Euro per quarter. The former is statistically significant at the 10 percent level, the latter at the 1 percent level. Table A.3 replicates the analysis for additional labor market outcomes of the children. A parental stroke leads to a statistically significant reduction in the number of days employed per quarter by 1.9 (2.8 percent), in the daily wage in Euro by 1.8 (-3.5 percent), and in the likelihood of full-time employment by 2.4 percentage points (-3 percent).
} 
to provide informal care to their parents. Second, children transfer financial resources to their parents to compensate for the earnings loss associated with the health shock. This would cause an increase in their own labor supply. In the following, we employ a series of tests designed to differentiate between the "care shock" and the "income shock". We also inspect the effect of a parental stroke on health outcomes of adult children to study potential consequences of a parental health shock besides those on labor outcomes.

\subsection{Children after a fatal parental shock ("no care shock")}

We focus on parental health shocks which are fatal and hence do not lead to care obligations for adult children. If it is the provision of informal care which causes the negative labor market effect among children after a non-fatal parental stroke, we would not expect a negative effect after a fatal parental shock. We define fatal shocks as strokes or heart attacks after which the parent dies within seven days. Our results in Figure 6 show no significant effects of a fatal parental shock on children's labor market outcomes. This is in line with our expectation that it requires a surviving parent in need of care to cause a reduction in the labor supply of the adult child.

\subsection{Children of already retired parents ("no income shock")}

As documented in Section 4.1, parents suffer a substantial loss in labor earnings after the health shock. In principle, adult children's labor supply could provide insurance against an income shock to the parent, i.e. when parents experience an income reduction due to a stroke, their adult children may compensate for the income loss by increasing their labor supply. If this was the case, our estimates in Figure 4 would present a mix of two opposing forces: A reduction in labor supply due to the increase in (informal) care, and an increase in labor supply to compensate for the parental income loss. To address this issue, we repeat our analysis in Figure 4 for a group in which the income channel is shut off: Parents who have been already retired prior to the stroke should not experience a loss in income. Figure 7 displays the results from this analysis. The effect for children whose affected parents are already retired is similar to the effect for the entire sample. This indicates that income compensation through adult children plays only a minor role in our population. Thus, this result is in line with explanations based on the provision of informal care which causes the negative labor market effects of adult children.

\subsection{Health outcomes of children after a parental stroke}

A parental health shock may also have adverse consequences for the well-being of the children. The deterioration of parents' health per se might have a direct negative impact: Children may worry about their parent and develop stress-induced health issues. 
Further, the provision of informal care is known to be psychologically and physiologically challenging (Bom et al., 2019). We examine health outcomes of daughters and sons after a parental stroke. Any impact on children's health could represent another causal channel beyond an "allocation of time" effect through which a parental health shock could affect children's labor supply. Figure 8 shows the effect of a parental stroke on two measures for children's health. The dependent variable in Panel (a) is a broad measure for total health care spending (sum of medical attendance in the outpatient sector plus medical drugs). In Panel (b), the outcome is a specific measure for the spending on medical drugs related to the nerve system (e.g. anti-depressants). We do not find evidence for negative health consequences for adult children resulting from a parental stroke. This speaks against a causal mechanism which operates through increased mental stress following a parental stroke on adult children's labor supply.

\subsection{Who cares more?}

We now investigate whether treatment effects are heterogeneous across different groups of children. We distinguish between subgroups based on the sex of the child, the geographic

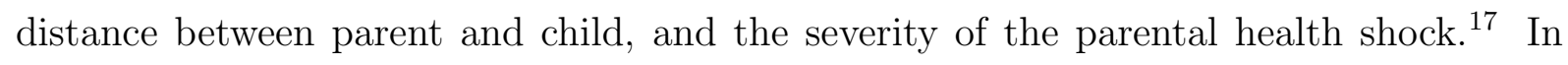
Table 2, we summarize for these sub-samples the effects of a parental stroke averaged over the twelve post-shock quarters.

\subsubsection{Sex of the child}

Given the survey evidence that caregiving is disproportionately provided by women, we now investigate whether the labor market consequences of a parental stroke are different for daughters and sons. The estimates in Panel (a) of Table 2 provide evidence that the negative labor market effect of a parental stroke is more pronounced for daughters compared to sons. Daughters experience, on average, a statistically significant reduction in their quarterly earnings by 255 Euro per quarter. In contrast, the corresponding point estimate for the effect on sons' earnings is smaller and not statistically distinguishable from zero.

To study the dynamics of the effects in more detail, we present the effects over the twelve quarters before and after a parental stroke by the sex of the child in Appendix Figure A.1. For daughters, we find a statistically significant reduction in the probability of employment by 4 percentage points (6 percent) one year after the stroke. This effect tends to become smaller and not distinguishable from zero the further we move away from the shock. In contrast, the negative effect on daughters' labor earnings stays relatively

\footnotetext{
${ }^{17}$ Child parity would be another interesting heterogeneity. However, due to data limitations on children born before 1974, we cannot measure parity without error. Therefore, we refrain from analyzing heterogeneity by parity/singleton status.
} 
constant throughout the post period. For sons, we observe point estimates for the effects on employment and labor earnings in the twelve quarters after a parental stroke that are not statistically distinguishable from zero.

\subsubsection{Geographic distance between child and parent}

Next, we consider geographical distance between the child and the parent who suffers a stroke. Distance is an important determinant for the cost of caregiving. 18 We expect that children living close to their parents are ceteris paribus more likely to provide care, and reduce their labor market activities to a larger extent. To test this hypothesis, we construct two sub-samples of children. One sample contains only children who live in the same zip-code as the affected parent ('local children'), while the other sample comprises those living further away ('distant children'). We measure the zip-code four quarters prior to the shock.

Panel (b) of Table 2 depicts the effects on the labor market outcomes of local and distant children separately. As expected, we find the treatment effect to be larger in both absolute and relative terms for children living close to their parents. Over the entire post-shock period (i.e., over the 12 quarter after the stroke), these children are on average 2.8 percentage points less likely employed, and earn on average around 205 Euro less per quarter. For children living further away, estimated treatment effects are not statistically different from zero. This underpins that the geographical distance between the affected parent and the children matters with respect to providing care.

\subsubsection{Children whose parents receive care allowance}

Next, we analyze treatment effect heterogeneity by the level of parental care allowance receipt. Parental care allowance receipt provides an objective measure of the caring needs of a parent hit by a stroke. However, the results presented here should be interpreted with caution, given that this analysis requires the additional assumption that care allowance receipt is unrelated to the decision of providing informal care or buying formal care arrangements. Furthermore, we want to highlight that although the share of caredependent parents rises sharply after a stroke, the overall number of recipients is modest, with around 20 percent of all stroke-affected parents receiving the care allowance after the shock. This is aggravated by the fact that the data on care allowance receipt is only available until 2012.

Panel (c) in Table 2 shows children's labor market outcomes split by parental care allowance receipt one year after the stroke. In total, only around a fifth of children in our sample have parents who receive a care allowance at this point. Overall, we find the

\footnotetext{
${ }^{18}$ Konrad et al. (2002) study game-theoretically the residential choice of siblings and predict that firstborn children locate further away from their parents to avoid care responsibilities. We find no significant difference in parent-child distance between the youngest and oldest child.
} 
post-shock coefficients for children with parental care allowance receipt to be much larger compared to children without parental care allowance receipt. However, due to the small sample size the estimates are rather imprecise, and somewhat miss commonly used levels of statistical significance. Nevertheless, the results are consistent with a larger negative impact of a parental stroke on children's labor market outcomes when caring needs are higher.

\section{Sensitivity analysis}

We conduct further analyses to show that our empirical results are robust to i) applying an identification strategy with a fixed control group as in Fadlon and Nielsen (2020, 2019), and to ii) restricting our sample to surviving parents only. The detailed set of results of these analyses can be found in Appendix A.3.

\subsection{Empirical approach with explicit control group}

In our main analysis, the control group varies at each event quarter. As a robustness check we now use a fixed control group over all event quarters. More precisely, we compare the outcomes of individuals whose family experiences a parental health shock in time $\tau$ with those of families, who experience the same shock twelve quarters in the future, i.e. in $\tau+12$ (similar to Fadlon and Nielsen $(2020,2019)$ ). This is particularly useful because parental health outcomes slightly worsen in the quarters right before the health shock (see discussion earlier). We do not want to include these individual-quarter observations in the set of controls. In our main approach, these individual-quarter observations can enter the control group in any event quarter. Exploiting a fixed control group of families, who experience the health shock twelve quarters in the future, we can transparently show the dynamic effects for the event quarters in which this control group provides a "clean" counterfactual.

The results for this robustness check are presented in Appendix Section A.3.1. The estimated coefficients for the dynamic treatment effect up to ten quarters after the reference quarter are very similar across the two approaches (see, for example, Panels (a) and (b) in Appendix Figures A.3 and A.5. Only the estimated treatment effects for the event quarter 11 illustrate clearly that we estimate a drop in hospital days and health-care spending due to the "contaminated" counterfactual. Conversely, this indicates that no contamination is present in the quarters 0 to 10 , allowing for a credible estimation of the causal effect for these quarters. In addition, the size of the contamination appears to be small when compared to the post-shock effect, with a noise-to-signal ratio of 5 to 10 . 


\subsection{Excluding cases where the affected parent dies within three years}

In our main analysis, we include all families in which the affected parent does not die within a week of the respective health shock. Around $10 \%$ of the surviving parents die within three years after their health shock, which is the time horizon of our analysis. We provide a robustness check using only families in which the affected parent stays alive for at least three years following the respective health shock. The results for this robustness check are provided in Appendix A.3.2. Restricting our sample to surviving parents does not change our results.

\section{Liberalization of the formal care market}

In our analysis above, we uncover negative impacts of a parental stroke on the labor market activities of children based on health shocks that occurred between 1998 and 2017. In 2007 , in the middle of the time period of our study, a substantial liberalization of the formal care market took place, sharply increasing the supply of migrant care workers in Austria. In this section, we investigate whether this policy intervention attenuated the negative effects of a parental stroke on adult children's labor market activities.

\subsection{The reform}

In July 2007, the Austrian government implemented a set of reforms to liberalize the formal care market. A particular goal was to allow private households to hire care workers. Therefore, a legal basis for home care work (the so-called "24h care work") was established. This type of service had already existed before, but without any legal basis. The reform turned this small gray economy into a formalized system of privately hired home care workers. A second cornerstone of the reform was the exemption of foreign care workers from the existing labor market restrictions for citizens of Central and Eastern EU member countries. With this reform, care workers from the new EU member states (the Baltic States, Czech Republic, Hungary, Slovenia, Slovakia, after 2007 also Bulgaria and Romania) gained access to the Austrian care market. They predominantly offered their care services as self-employed under the new legal framework of the "24-hour care work" (Österle and Bauer, 2016).

\subsection{Inflow of migrant care workers}

There is no ideal data source to document the inflow of migrant care workers. However, the combination of different data sources leads to clear conclusions. Figure 9 documents the size of the inflow of foreign care workers to Austria using various sources of administrative 
data. The panels on the left display the group of EU-11 nationals 19 , whereas the panels on the right refer to the group of Austrian nationals. The two top Panels (a) and (b) show the total number of employed female care workers for the two groups ${ }^{20}$ For neither group we observe a discontinuous increase in dependent employment after the reform in 2007. In the two middle panels, we display the number of self-employed females from two different data sources. In circles, we show the number of self-employed females as registered in the ASSD (Austrian Social Security Data), and in squares we show the number of self-employed females recorded in the BALI (budget, labour market and benefit receipt information) online database. While the ASSD tracks the number of self-employed individuals also prior to 2007, it comes with the disadvantage of not recording the sector the self-employed are working in. BALI does record the sector, but is not available prior to 2008. Both series in Panel (c) display a very strong and almost identical increase in the number of self-employed women from the EU-11 after the reform, rising from 10,000 in 2008 to around 40,000 in 2012. Studying the series in circles from the ASSD, we see that this rise in EU-11 self-employed females starts exactly after the implementation of the care reform in 2007. In contrast, Panel (d) (which displays Austrian self-employed women only), shows only a very small increase over time, with no trend break around the time of the reform. In the bottom panels we exploit the fact that BALI records the economic sector, allowing us to distinguish between all self-employed women, and those working in "other personal service activities" (which is the category under which selfemployed care workers fall). Panel (e) shows that almost all self-employed women from the EU-11 work in the care sector, and confirms the very strong increase in self-employed care workers from the EU-11 after 2007. In contrast, almost no increase in self-employed Austrian women working in "other personal service activities" takes place around that time. To conclude, Figure 9 documents a strong inflow of predominantly self-employed foreign care workers to Austria after the care reform in 2007. ${ }^{21}$

\subsection{Size of the grey economy before the reform}

It is possible that some of the self-employed foreign care workers who registered after 2007 worked illegally in Austria prior to the reform. So rather than inducing a real supply shock of care workers the reform might have just led to a legalization of foreign care workers who already provided their services on an unregistered basis. The home care reform was implemented on July 1, 2007 but there was a transitional period until June 30, 2008 in

\footnotetext{
${ }^{19}$ EU-11 includes citizens from the Central, Eastern and Baltic European member states that accessed the EU in 2004 and thereafter: the Czech Republic, Estonia, Latvia, Lithuania, Hungary, Poland, Slovenia, and the Slovak Republic in 2004; Bulgaria, Romania in 2007; and Croatia in 2013.

${ }^{20}$ This includes all employees in the ASSD with a NACE category of 8710 (residential nursing care activities), 8730 (residential care activities for the elderly and disabled), 8790 (other residential care activities), or 8810 (social work activities without accommodation for the elderly and disabled).

${ }^{21}$ Figure A.4.4 in the Appendix replicates Figure 9 for male care workers. As we can see, male (foreign) care workers play basically no role on the formal care market in Austria.
} 
which amnesty was granted for unregistered home care workers (Larsen et al., 2009). In the left panel of Appendix Figure A.10 we plot the number of EU-11 self-employed women on a quarterly basis (ASSD). The number of EU-11 self-employed women steadily increases by around 1,000 to 2,000 per quarter after the implementation of the reform in the third quarter of 2007. In addition, we can see that there is a discrete jump in the number of EU-11 self-employed women around the time when amnesty ends. This number jumps from about 7,000 in the second quarter to 13,000 in the third quarter of 2008. We assume that the discrete increase by around 6,000 registered EU-11 self-employed women around the end of amnesty provides an upper bound for the legalization effect. This legalization effect appears to be small compared to the overall increase of EU-11 self-employed women after the reform, rising steadily to around 40,000 in 2012 (see Panel (e) Figure 9). This is corroborated by a comprehensive study based on interviews and field studies, which concludes that the post-reform number of foreign care workers considerably exceeds the estimated level of previous illegal employment in this sector (Österle and Bauer, 2016).

\subsection{Cost of foreign care workers}

Why became self-employed foreign care workers so popular in Austria? A driving force behind the rise in demand for self-employed foreign care workers is their relatively low remuneration: The costs for an equivalized day of formal care provided by a self-employed care worker are around $20 \%$ lower compared to hiring a dependent care worker (FamiraMühlberger, 2017) 22 Furthermore, the vast majority of the self-employed foreign care workers work on specific rotational shifts: The foreign care workers usually come as livein carers and return to their home country on a biweekly rotation (Österle and Bauer, 2016). Thus, they do not need to cover Austrian living expenses, but the rather favorable costs of living of their Eastern European home countries ${ }^{23}$ Unfortunately, we cannot study the wage differential between the EU-11 self-employed and Austrian care workers directly in our data, since the ASSD does not record the wages of self-employed. However, some of the self-employed foreign care workers file an income tax return in Austria. We do have access to tax return data from 2008-2012. In this data, we are able to identify around $30 \%$ of the EU-11 female self-employed registered in the ASSD. Figure 10 compares the annual gross income of self-employed females from EU-11 to the annual gross earnings of full-time dependent female care workers in Austria. We find the annual gross income of the self-employed females from EU-11 to be substantially lower (around 8,000 Euro) compared to dependent female care workers (around 20,000 Euro).

\footnotetext{
${ }^{22}$ The authors argue that this is mostly due to the legal status as self-employed, which makes these workers not subject to collectively bargained wages or rigid working time provisions that apply to dependent care workers.

${ }^{23}$ More than 80 percent of the foreign care workers come from Slovakia or Romania, two countries which have much lower costs of living compared to Austria (Österle and Bauer, 2016, Famira-Mühlberger, 2017).
} 
Finally, finding and hiring a self-employed care worker from the EU-11 was made simple and easy. After the reform, private agencies assisting Austrian families in the placement of a self-employed foreign care worker mushroomed. Famira-Mühlberger (2017) estimates that around 600 of those agencies existed in Austria in 2016. In addition, the reform of 2007 was covered extensively by Austrian newspapers ${ }^{24}$ Thus, the salience of the reform was large, and it seems likely that many Austrian families with caring responsibilities were aware of the new possibilities to find formal care.

Overall, the reform of 2007 drastically changed the availability and affordability of formal care in Austria. In the following, we exploit this policy change to examine whether this positive supply shock muted the negative labor market effects on adult children after a parental stroke.

\subsection{Effect of the reform on children's labor market responses to increasing parental care needs}

We now ask the question, whether a parental stroke has a different impact on adult children's labor supply before and after the reform in 2007. In a first step, we simply split the sample by the year of the shock. Columns (1) and (2) of Panel (d) in Table 2 summarize the event study results for children whose parents suffered a stroke from 2003 to 2007, whereas columns (3) and (4) display the results for those with parental strokes from 2008 to 2012. The effects of a parental stroke on children's employment and earnings are sizable and negative if the stroke occurred prior the implementation of the reform. In contrast, parental strokes that occurred in the years thereafter do not impact the employment or earnings of their children 25 However, we cannot rule out that other changes between these two time periods apart from the care reform took place, which may have affected children's labor market response to parental strokes (e.g., changes in the overall economic or labor market situation).

In order to account for other potential time-varying factors that impacted labor market outcomes apart from the reform, we want to have a "control" group of individuals whose labor market outcomes provide a reasonable counterfactual for children who experience a parental stroke in absence of the reform. Our results in Section 4.2 suggest that a parental heart attack has a negligible effect on the need for care, especially relative to parents who suffer from a stroke. Therefore, the increased availability of formal care workers after the care reform should be irrelevant (or matter little) for the labor market responses of children whose parents experience a heart attack. At the same time, children with a parental heart attack should be subject to the same general changes in the labor market

\footnotetext{
${ }^{24}$ We provide an analysis of press articles reporting about the reform in the Appendix Section A.4.1.

${ }^{25}$ We also examine whether strokes before the reform happen to be more severe, but we do not find any meaningful differences in changes of parental health outcomes suffering from a stroke before versus after the reform.
} 
over time.

We estimate a difference-in-difference-in-differences (DDD) model that exploits variation in parents' need for as well as availability of formal care along three dimensions: (a) between time periods before and after the health shock, (b) between families that experience a stroke compared to a heart attack, and (c) between families that experience the shock before or after the implementation of the reform:

$$
\begin{aligned}
& O_{i, t}=\gamma_{0}+\gamma_{1} \text { Post }_{i t}+\gamma_{2} \text { Stroke }_{i}+ \gamma_{3} \text { AfterReform }_{t} \\
&+\gamma_{4} \text { Post }_{i t} \cdot \text { Stroke }_{i}+\gamma_{5} \text { Post }_{i t} \cdot \text { AfterReform }_{t}+\gamma_{6} \text { Stroke }_{i} \cdot \text { AfterReform }_{t} \\
&+\eta \text { Post }_{i t} \cdot \text { Stroke }_{i} \cdot \text { AfterReform }_{t}+\lambda_{c, t}+\epsilon_{i, t}
\end{aligned}
$$

where the dummy variable Stroke $_{i}$ takes the value 1 if the parent of individual $i$ suffers from a stroke, and 0 if the parent has a heart attack. Post ${ }_{i t}$ takes the value 1 for quarters after the parental health shock of individual $i$, and 0 before. AfterRe form fis $_{\text {in indicator }}$ equal to one if the year is after the reform and 0 if before. $\lambda_{c, t}$ are quarter-by-cohort fixed effects. Standard errors are robust and clustered at the individual level.

The main parameter of interest is $\eta$. If the increased availability of care workers muted the negative effects of a parental stroke on their children's labor market outcomes, then the coefficient of the triple interaction term Post ${ }_{i t} \cdot$ Stroke $_{i} \cdot$ AfterReform $_{t}, \eta$, would be positive. The identifying assumption is that, on average, the difference between the outcomes of families experiencing a stroke and families experiencing a heart attack would have evolved similarly before and after the implementation of the reform in the absence of the health shock.

We include observations in the 12 quarters before $($ Post $=0)$ and after the parental health shock occurs $($ Post $=1)$ and only include those children who are observed in all of these quarters. In the main estimation, we restrict our sample to all children whose parents suffered a stroke or heart attack in the five years before $($ AfterReform $=0)$ or after 2007 (AfterReform $=1$ ) ${ }^{26}$ This implies that children who experience a parental stroke shortly before the reform might still be affected by the increased availability of formal care in some quarters of their post-shock period. For example, a child whose parents had a health shock in 2006 might switch to $24 \mathrm{~h}$ care work after the 2007 reform and hence within our 3 -year post-shock period. In order to avoid that individuals in the "control" (AfterReform =0) group are partly treated by the reform, we provide an alternative estimation in which we only include children who experienced a parental health shock before 2005 and thus, are unaffected by the reform throughout the 3-year post-shock period (labeled as 'W/O late controls' in Table 3).

Table 3 displays the estimated coefficients on the triple interaction term in the DDD

\footnotetext{
${ }^{26}$ We provide additional results in which we narrow down this window to four years.
} 
model described in equation (2). Appendix Table A.4 provides the estimated coefficients for all variables in the model. We focus on the analysis in Panel A which considers children who experience a parental health shock in the five years around the reform. Columns (1) and (2) show positive and economically significant coefficients for both labor market outcomes. The coefficient of interest is statistically significant at the ten percent level in the case of employment. Our result in column (1) implies that the increased availability and affordability of formal care due to the reform in 2007 reduced the negative effect of parents' care dependency on children's employment by 3.6 percentage points. If we only include children in the "control" group (AfterReform =0) who cannot benefit from the reform throughout the three years after their parents' health shock in columns (3) and (4) (labeled as 'W/O late controls'), both coefficients increase in size and statistical significance. We find that the reform significantly reduced the negative effect of a sudden increase in parental dependency on children's employment by 6.2 percentage points. Similarly, the negative effect on children's quarterly labor earnings decreases significantly in size by 373 Euro. In Panel B, we restrict the sample to children who experienced a parental health shock in the four years before and after the reform. The results are very similar in size and significance if we narrow down the window around the reform to four years.

To sum up, we find that the care reform with its large increase in the availability of formal care helped children to avoid the negative impact of a parental stroke on their labor market outcomes. This indicates that migrant care workers who provide $24 \mathrm{~h}$ care at home act as substitutes for adult children's informal care work, a factor that can be influenced by migration policies.

\section{Conclusions}

Many societies around the world are aging rapidly, facing the prospects of a population pyramid turning upside down. One of the key challenges of an aging population is the increasing need for care. LTC provisions in many OECD countries are characterized by a mix of informal and formal care arrangements. Adult children are often important providers of informal care to their parents, which in turn may affect their labor market outcomes and well-being. Understanding the impact of providing care to a sick relative is crucial when designing and evaluating long-term care policies, such as expansions of public LTC.

Against this background, we examine how parental health shocks affect the labor market and health outcomes of their adult children. Our study exploits sudden parental health shocks (strokes and heart attacks) to evaluate their effect on the employment and earnings of adult children. We estimate event study models, and find significant negative effects of strokes on labor market outcomes of adult children, but not of heart attacks. 
With a 2.5 percentage points (or 3.5 percent) reduction in employment and a 3.9 percent decrease in earnings one year after the stroke, the effects also appear to be economically non-negligible. The analysis reveals that the negative labor market effects of a parental stroke are concentrated among daughters, stronger for those living close to their parents, and more pronounced when the affected parent receives a care allowance.

Exploring potential channels behind the negative effects of a parental stroke on children's labor market outcomes, we first document that only strokes result in a sharp increase in parental care dependency but not heart attacks. This points towards the provision of informal care as a relevant factor for the negative labor market effects of children after a parental stroke. Furthermore, we study the consequences of fatal parental shocks, which by definition do not trigger care requirements. Using the sample of fatal shocks, we do not find negative effects on children's labor market outcomes. These results are in line with explanations based on the time-consuming nature of providing informal care to elderly parents. The larger negative estimates for children who live closer to their parents underpin this reasoning. In sum, our analysis suggests that it is indeed care obligations that causes the negative labor supply effects after a parental stroke.

Finally, we examine whether public policies can mitigate the negative labor market effects stemming from a parental health shock. We exploit a reform that loosened restrictions on privately hired (foreign) care workers, which led to a sharp increase of migrant care workers in Austria. Using a triple-difference strategy, we find that children who are exposed to the increased availability of formal care are able to avoid the negative labor market effects of a parental stroke. This suggests that the availability and affordability of formal care matters for the decision which care mode families choose, and can be manipulated by policymakers. Overall, we show that migrant care workers can substitute informal care, which is mostly performed by female family members.

Our study carries important implications for public policies. First, it shows that the well-known gender inequality in informal care work spills over to gender inequality in the paid labor market. Furthermore, we document how institutional changes in formal care markets can have a lasting impact on the availability of formal care arrangements, which has the potential to help adult children avoid the negative labor market consequences of providing informal care.

Due to data limitations, we can only study "younger" children (about 30 years old at the time of the parental shock). We consider this an important life period to study since these children are at the beginning of their working careers. In future research, it would be interesting to study the impact of parental health shocks along the entire children's life cycle. 


\section{References}

Akerlof, George and Rachel Kranton (2000), 'Economics and Identity', Quarterly Journal of Economics. 115(3), 715-753.

Bauer, Michael and Alfonso Sousa-Poza (2015), 'Impacts of Informal Caregiving on Caregiver Employment, Health, and Family', Journal of Population Ageing. 8, 113-145.

Black, Nicole, David W. Johnston and Agne Suziedelyte (2017), 'Justification Bias in SelfReported Disability: New Evidence from Panel Data', Journal of Health Economics. 54, 124-134.

Bolin, Kristian, Björn Lindgren and Nils-Petter Lundborg (2008), 'Your Next of Kin or Your Own Career? Caring and Working Among the 50+ of Europe', Journal of Health Economics. 27(3), 718-738.

Bom, Judith, Pieter Bakx, Frederik Schut and Eddy van Doorslaer (2019), 'Health Effects of Caring for and about Parents and Spouses', Journal of the Economics of Ageing. 14, 1-12.

Borusyak, Kirill and Xavier Jaravel (2017), Revisiting Event Study Designs, mimeo.

Carmichael, Fiona, Susan Charles and Claire Hulme (2010), 'Who Will Care? Employment Participation and Willingness to Supply Informal Care', Journal of Health Economics. 29(1), 182-190.

Chandra, Amitabh and Douglas O. Staiger (2007), 'Productivity Spillovers in Health Care: Evidence from the Treatment of Heart Attacks', Journal of Political Economy. 115(1), 103-140.

Ciani, Emanuele (2012), 'Informal Adult Care and Caregivers' Employment in Europe', Labour Economics. 19(2), 155-164.

Cortés, Patricia and Jessica Pan (2013), 'Outsourcing Household Production: Foreign Domestic Workers and Native Labor Supply in Hong Kong', Journal of Labor Economics. 31(2), 327-371.

Cortés, Patricia and Jessica Pan (2019), 'When Time Binds: Substitutes for Household Production, Returns to Working Long Hours, and the Skilled Gender Wage Gap', Journal of Labor Economics. 37(2), 351-398.

Cortés, Patricia and Jose Tessada (2011), 'Low-Skilled Immigration and the Labor Supply of Highly Skilled Women', American Economic Journal: Applied Economics. 3(3), 88123.

Crespo, Laura and Pedro Mira (2014), 'Caregiving to Elderly Parents and Employment Status of European Mature Women', Review of Economics and Statistics. 96(4), 693709 .

Dobkin, Carlos, Amy Finkelstein, Raymond Kluender and Matthew J. Notowidigdo (2018), 'The Economic Consequences of Hospital Admissions', American Economic Review. 108(2), 308-352. 
Doyle, Joseph J. (2011), 'Returns to Local-Area Health Care Spending: Evidence from Health Shocks to Patients Far From Home', American Economic Journal: Applied Economics. 3(3), 221-243.

Druedahl, Jeppe and Alessandro Martinello (2016), Long-Run Saving Dynamics: Evidence From Unexpected Inheritances, Lund University Working Paper No. 7, Lund University, Department of Economics.

Esping-Andersen, Gosta (1999), Social Foundations of Postindustrial Economics, Oxford University Press, Oxford, United Kingdom.

Fadlon, Itzik and Torben Heien Nielsen (2019), 'Family Health Behaviors', American Economic Review. 109(9), 3162-3191.

Fadlon, Itzik and Torben Heien Nielsen (2020), 'Family Labor Supply Responses to Severe Health Shocks', American Economic Journal: Applied Economics. (forthcoming), xxxxx.

Famira-Mühlberger, Ulrike (2017), Die Bedeutung der 24-Stunden-Betreuung für die Altenbetreuung in Österreich, Technical report, Austrian Institute of Economic Research, Vienna, Austria.

Famira-Mühlberger, Ulrike (2020), Pflegevorsorge in Gemeinden, Technical report, Austrian Institute of Economic Research, Vienna, Austria.

Farré, Lidia, Libertad Gonzalez and Francesc Ortega (2011), 'Immigration, Family Responsibilities and the Labor Supply of Skilled Native Women', B.E. Journal of Economic Analysis and Policy. 11(1), 34-71.

Fevang, Kverndokk and Roed (2012), 'Labor Supply in the Terminal Stages of Lone Parents' Lives', Journal of Population Economics. 25(4), 873-909.

Firgo, Matthias, Klaus Nowotny and Alexander Braun (2020), 'Informal, Formal, or Both? Assessing the Drivers of Home Care Utilization in Austria Using a Simultaneous Decision Framework', Applied Economics. 52(40), 4440-4456.

Garcia-Gómez, Pilar, Hans Van Kippersluis, Owen Donnell and Eddy Van Doorslaer (2013), 'Long-Term and Spillover Effects of Health Shocks on Employment and Income', Journal of Human Resources. 48(4), 873-909.

Gupta, Nabanita Datta, Kristin J Kleinjans Kleinjans and Mona Larsen (2015), 'The Effect of a Severe Health Shock on Work Behavior: Evidence from Different Health Care Regimes', Social Science \& Medicine. 136, 44-51.

Halla, Martin and Martina Zweimüller (2013), 'The Effect of Health on Earnings: QuasiExperimental Evidence from Commuting Accidents', Labour Economics. 24, 24-38.

Heger, Dörte and Torben Korfhage (2020), 'Informal Care to Parents and Labor Market Outcomes - Short- and Medium-Term Effects', Feminist Economics. (forthcoming), xxxxx.

Heitmueller, Axel (2007), 'The Chicken or the Egg? Endogeneity in Labour Market Participation of Informal Carers in England', Journal of Health Economics. 26(3), 536559. 
Jeon, Sung-Hee and R. Vincent Pohl (2017), 'Health and Work in the Family: Evidence from Spouses' Cancer Diagnoses', Journal of Health Economics. 52, 1-18.

Johnston, S. Claiborne, Daryl R. Gress, Warren S. Browner and Stepehen Sidney (2000), 'Short-term Prognosis after Emergency Department Diagnosis of TIA', Journal of the American Medical Association. 284(22), 2901-2906.

Kleven, Hendrik, Camille Landais and Jakob Sogaard (2019), 'Children and Gender Inequality: Evidence from Denmark', American Economic Journal: Applied Economics. (11), 181-209.

Kleven, Henrik, Camille Landais, Johanna Posch, Andreas Steinhauer and Josef Zweimüller (2019), 'Child Penalties Across Countries: Evidence and Explanations', AEA Papers and Proceedings. 109, 122-126.

Konrad, Kai, Harald Künemund, Kjell Lommerud and Julio Robledo (2002), 'Geography of the Family', American Economic Review. 92(4), 981-998.

Larsen, Christa, Angela Joost and Sabine Heid (2009), Illegale Beschäftigung in Europa. Die Situation in Privathaushalten älterer Personen: Illegal Employment in Europe. The Situation in Private Homes of the Elderly, Rainer Hampp Verlag, Augsburg, Germany.

Løken, Katrine V, Shelly Lundberg and Julie Riise (2017), 'Lifting the Burden: Formal Care of the Elderly and Labor Supply of Adult Children', Journal of Human Resources. 52(1), 247-271.

OECD (2017), Long-term Care Expenditure, OECD Publishing Paris 7, OECD.

Österle, August and Gudrun Bauer (2016), 'The Legalization of Rotational 24-hour Care Work in Austria: Implications for Migrant Care Workers', Social Politics: International Studies in Gender, State and Society. 23(2), 192-213.

Pezzin, Liliana E. and Barbara Steinberg Schone (1997), 'The Allocation of Resources in Intergenerational Households: Adult Children and Their Elderly Parents', American Economic Review. 87(2), 460-464.

Pezzin, Liliana E. and Barbara Steinberg Schone (1999), 'Intergenerational Household Formation, Female Labor Supply and Informal Caregiving: A Bargaining Approach', Journal of Human Resources. 34(3), 475-503.

Rellstab, Sara, Pieter Bakx, Pilar Garcia-Gómez and Eddy van Doorslaer (2020), 'The Kids are Alright - Labour Market Effects of Unexpected Parental Hospitalisations in the Netherlands', Journal of Health Economics. 69, 102275.

Riedel, Monika and Markus Kraus (2010), The Austrian Long-Term Care System, ENEPRI Research Report No. 69, Centre for European Policy Studies, Brussels, Belgium.

Schmidheiny, Kurt and Sebastian Siegloch (2020), On Event Studies and Distributed-Lags in Two-Way Fixed Effects Models: Identification, Equivalence, and Generalization, CEPR Discussion Papers 13477, Centre for Economic Policy Research, London, United Kingdom. 
Statistik Austria (2009), Zeitverwendung 2008/09: Ein Überblick über geschlechtsspezifische Unterschiede, Final report, Statistik Austria, Vienna, Austria.

Van Houtven, Courtney, Norma B. Coe and Meghan M. Skira (2013), 'The Effect of Informal Care on Work and Wages', Journal of Health Economics. 32(1), 240-252. 


\section{Figures (to be placed in the article)}

Figure 1: Social norm regarding the care provision to an elderly parent in selected countries

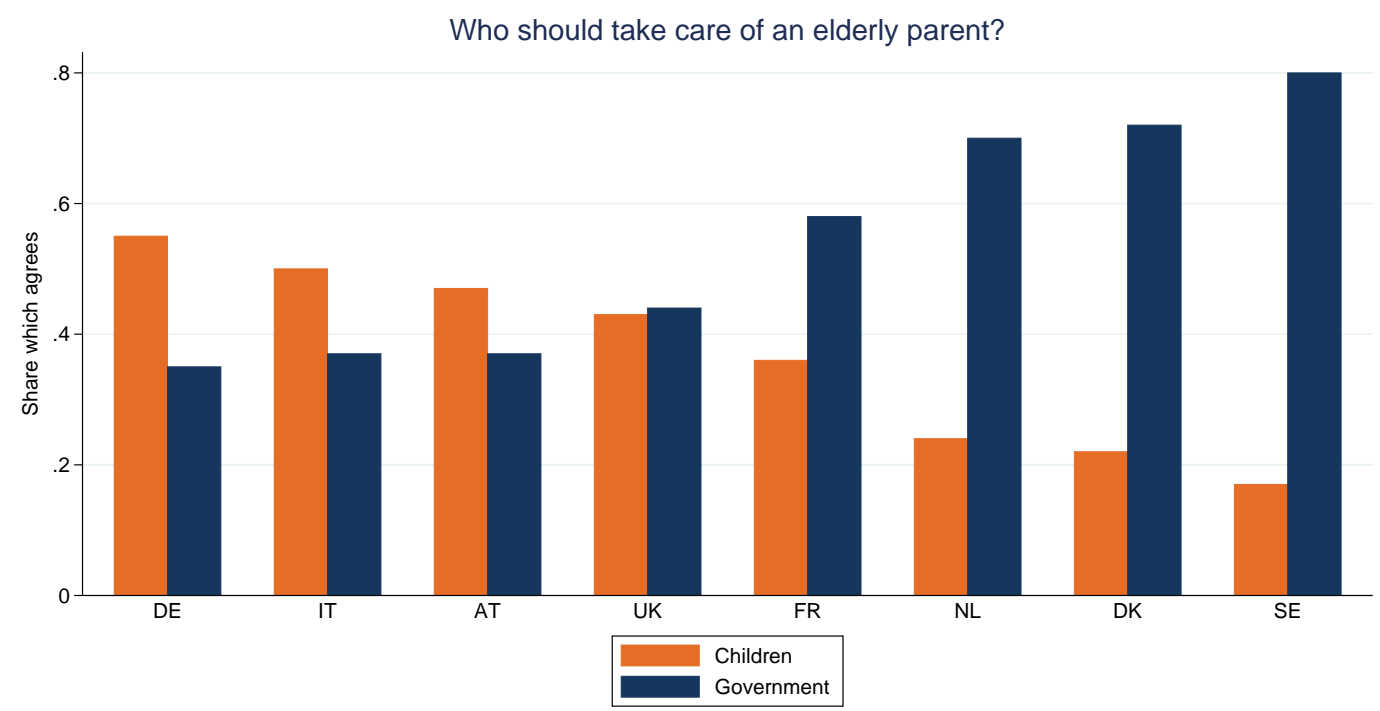

Notes: This figure is based on data from the Eurobarometer 67.3 (2007), which interviewed 28,660 citizens of the 25 countries in the European Union after the 2004 enlargement. All respondents were residents in the respective country, and aged 15 and over. The original survey questions is as follows 'Imagine an elderly father or mother who lives alone and can no longer manage to live without regular help because of her or his physical or mental health condition. In your opinion, what would be the best option for people in this situation?'. Respondents are given 5 options to choose from: 'They should live with one of their children' (1), 'One of their children should regularly visit their home, in order to provide them with the necessary care' (2), 'Public or private service providers should visit their home and provide them with appropriate help and care' (3), to 'They should move to a nursing home' (4). The graph shows the share of respondents (by country) which gave answer (1) or (2) (in orange), or answer (3) or (4) (in blue), respectively. 
Figure 2: Impact of parental stroke on parental health and employment

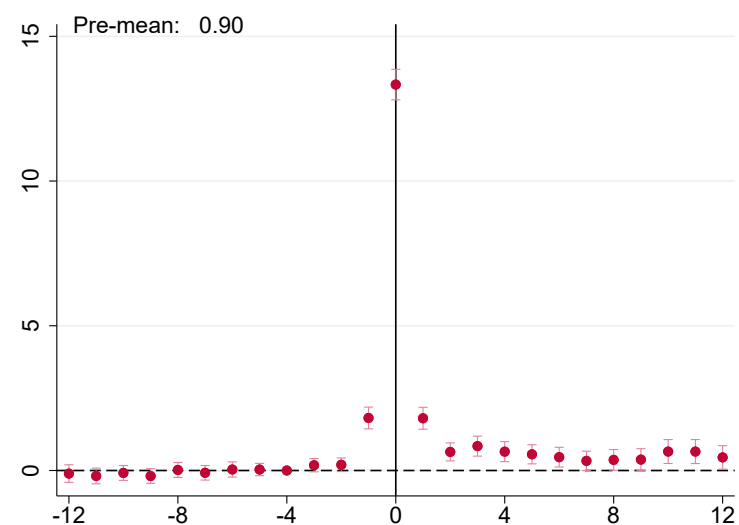

(a) Days in hospital

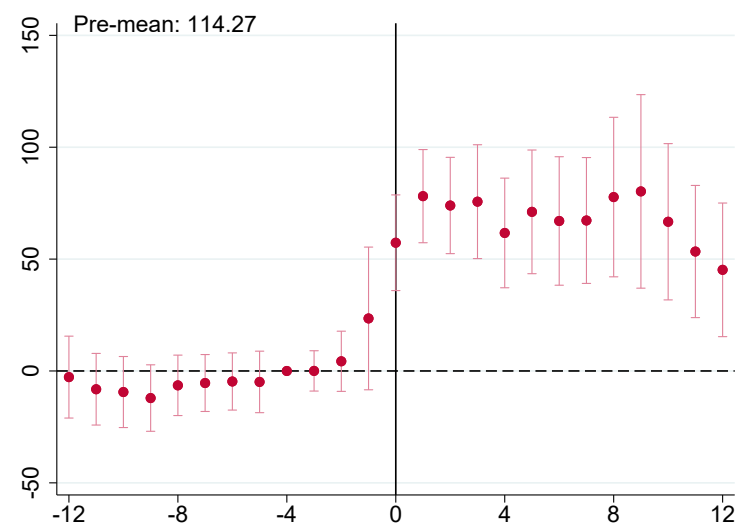

(c) Spendings on prescription drugs in Euro

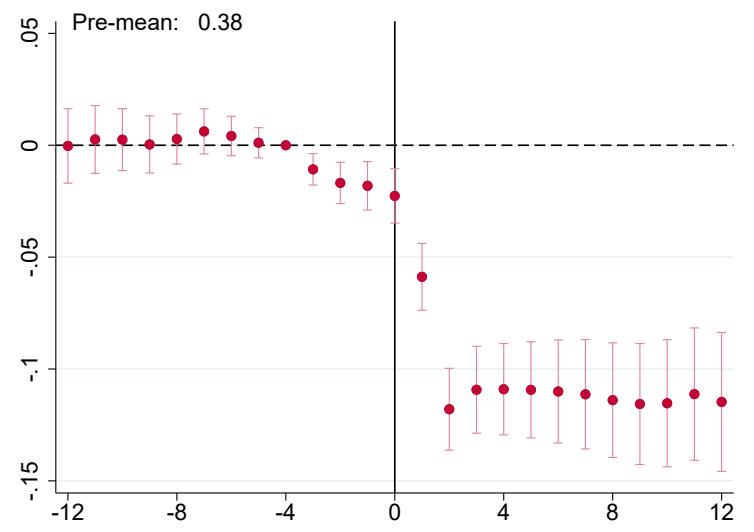

(e) Employment

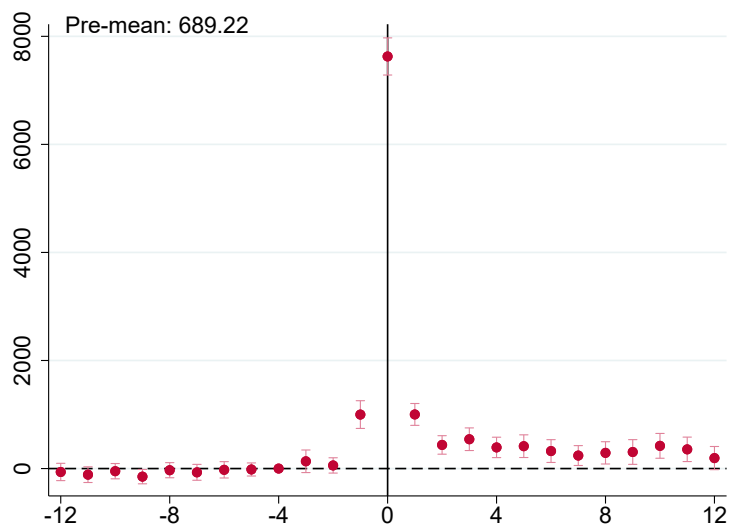

(b) Total health-care spendings in Euro

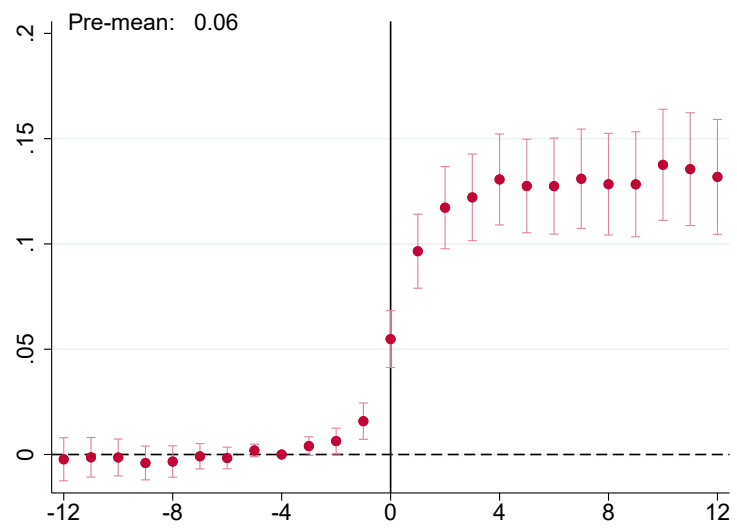

(d) Receipt of care allowance $(0 / 1)$

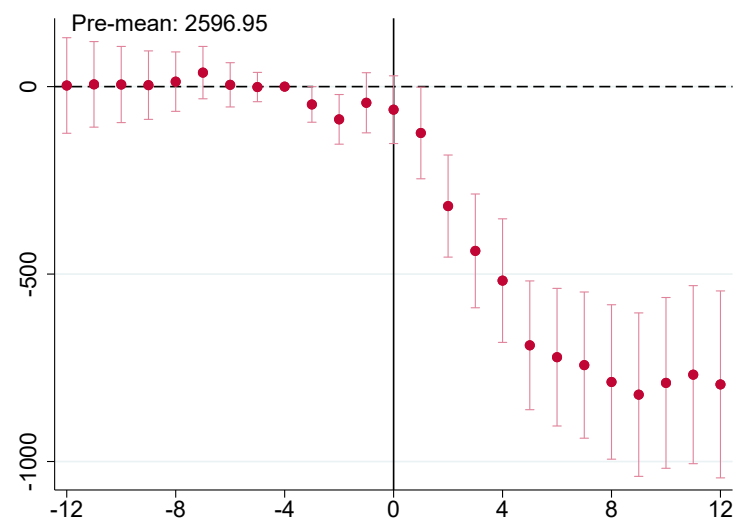

(f) Quarterly earnings in Euro

Notes: Each panel of the figure shows the event-study coefficients estimated from equation 1 (including 95 percent confidence intervals) of the parental stroke on the respective parental health or labor market outcome. Standard errors are clustered at the individual level. Pre-mean refers to the mean of the respective outcome variable four quarters prior to the parental stroke. 
Figure 3: Impact of parental heart attack on parental health and employment

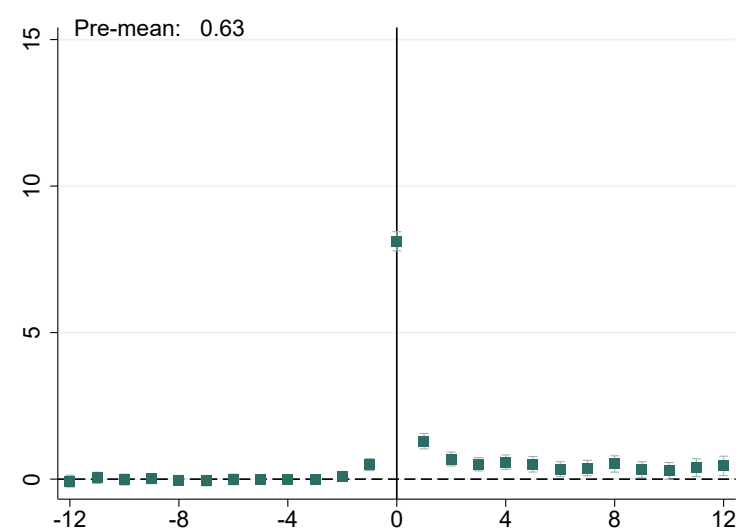

(a) Days in hospital

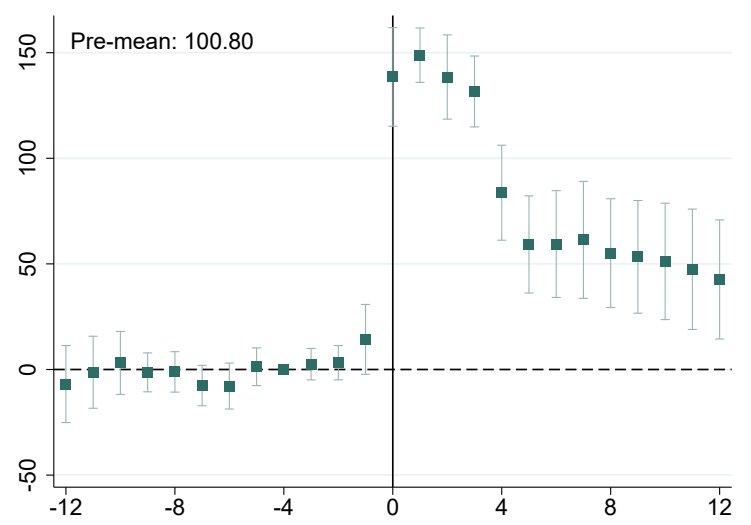

(c) Spendings on prescription drugs in Euro

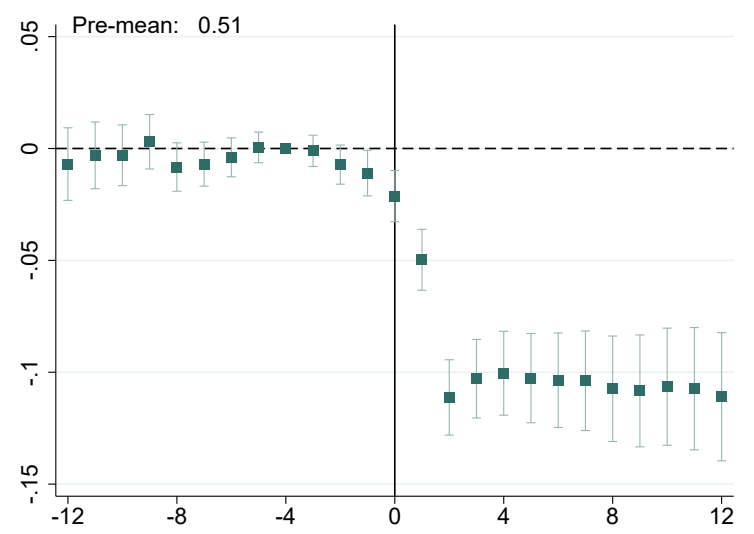

(e) Employment

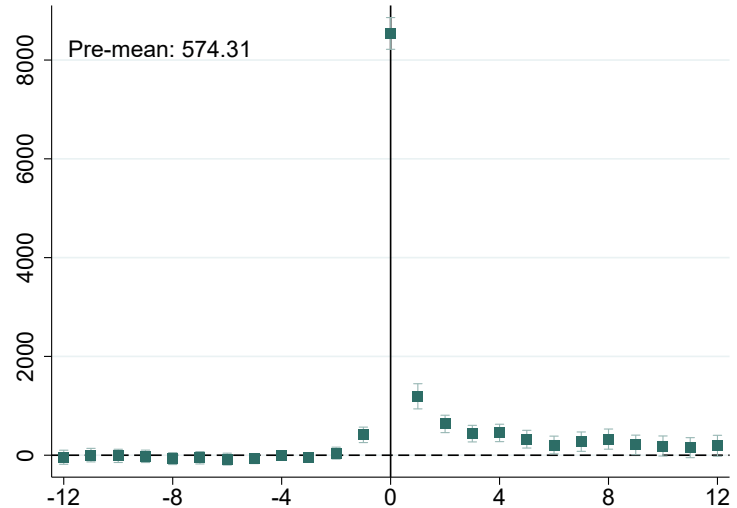

(b) Total health-care spendings in Euro

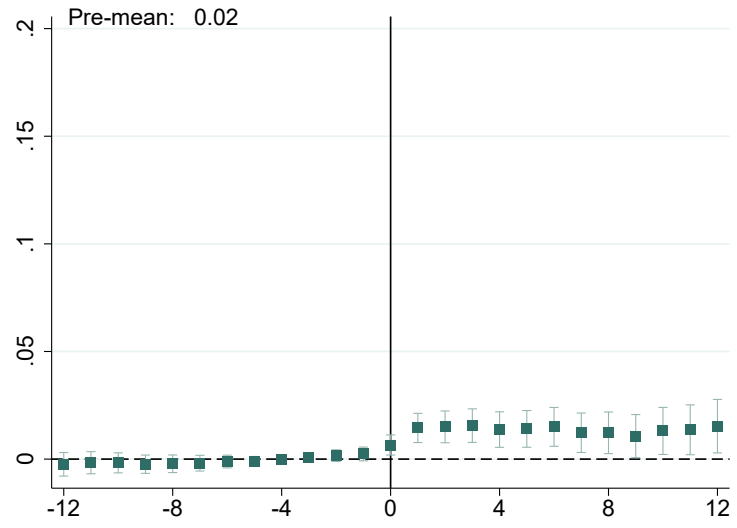

(d) Receipt of care allowance $(0 / 1)$

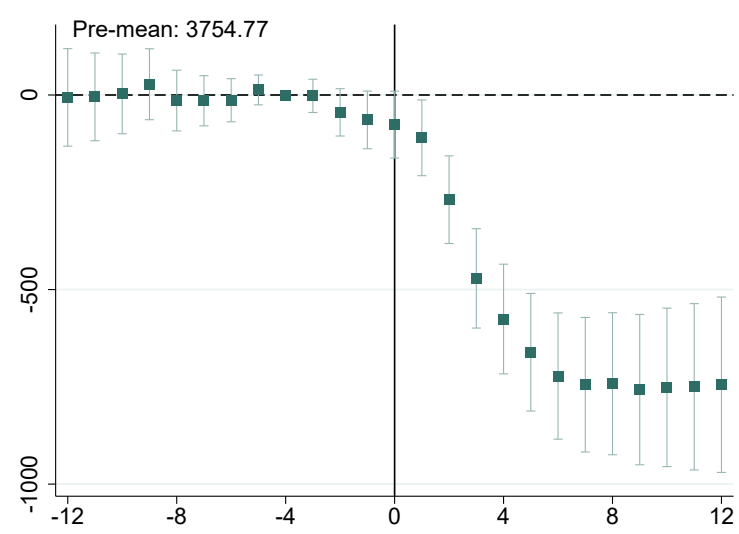

(f) Quarterly earnings in Euro

Notes: Each panel of the figure shows the event-study coefficients estimated from equation 1 (including 95 percent confidence intervals) of the parental heart attack on the respective parental health or labor market outcome. Standard errors are clustered at the individual level. Pre-mean refers to the mean of the respective outcome variable four quarters prior to the parental heart attack. 
Figure 4: Impact of parental stroke on children's labor market outcomes

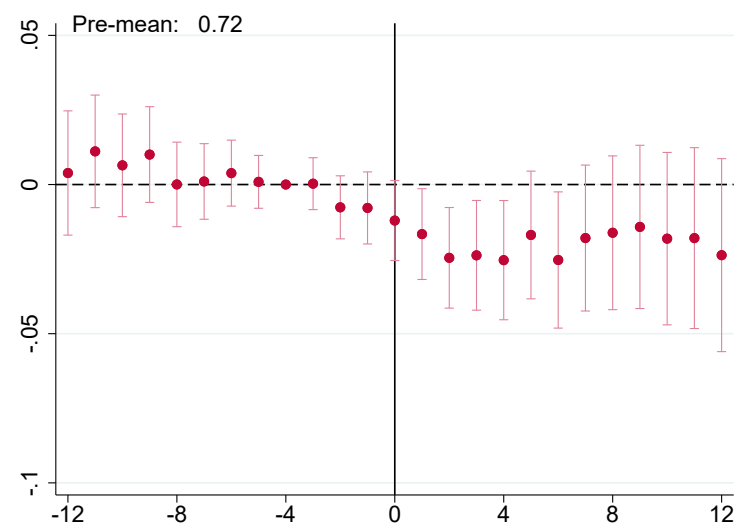

(a) Employment

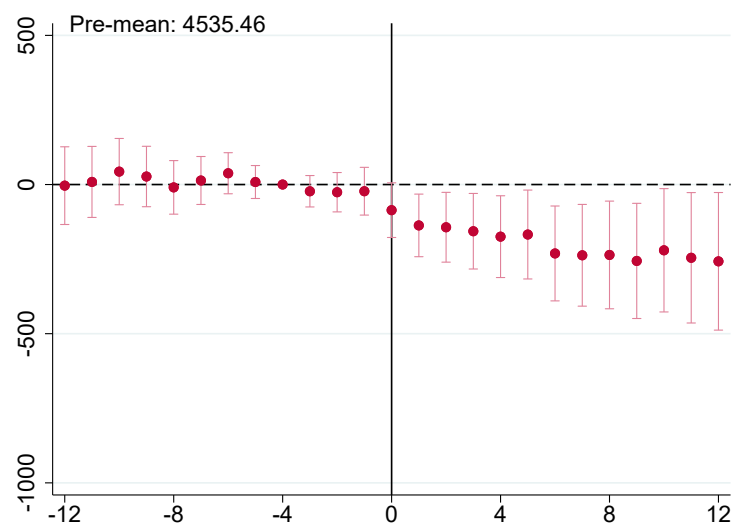

(b) Quarterly earnings in Euro

Notes: Each panel of the figure shows the event-study coefficients estimated from equation 1 (including 95 percent confidence intervals) of the parental stroke on the respective labor market outcome of the child. Standard errors are clustered at the individual level. Pre-mean refers to the mean of the respective outcome variable four quarters prior to the parental stroke.

Figure 5: Impact of parental heart attack on children's labor market outcomes

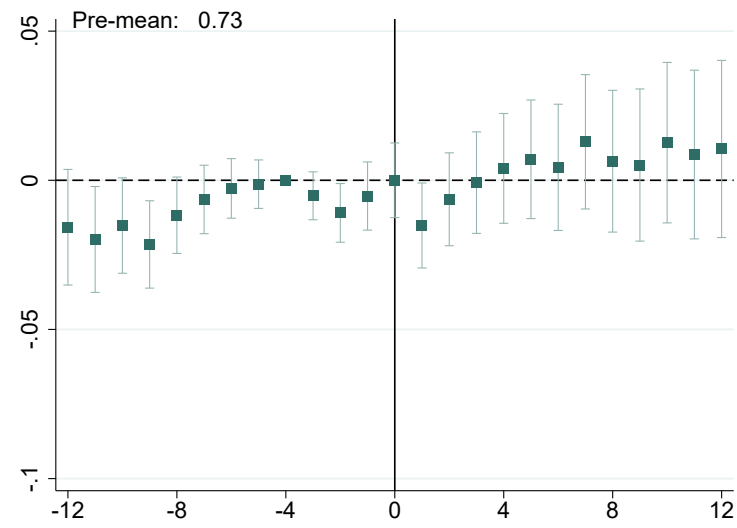

(a) Employment

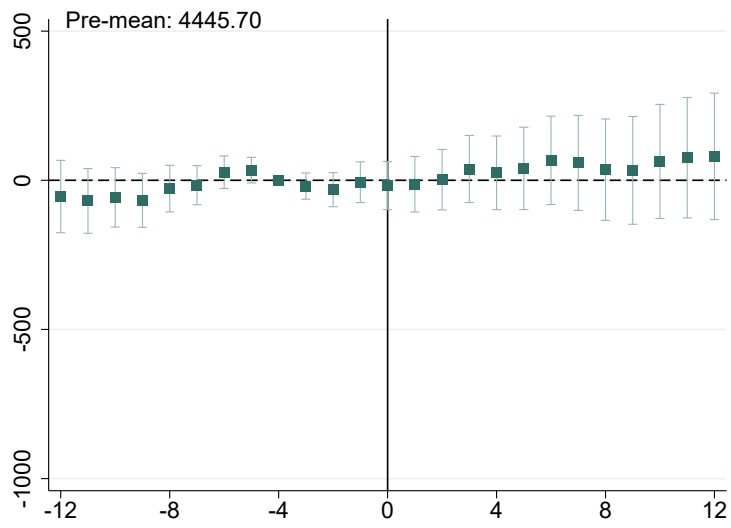

(b) Quarterly earnings in Euro

Notes: Each panel of the figure shows the event-study coefficients estimated from equation (1), including 95 percent confidence intervals of the parental heart attack on the respective labor market outcome of the child. Standard errors are clustered at the individual level. Pre-mean refers to the mean of the respective outcome variable four quarters prior to the parental heart attack. 
Figure 6: Impact of fatal parental shock on children's labor market outcomes

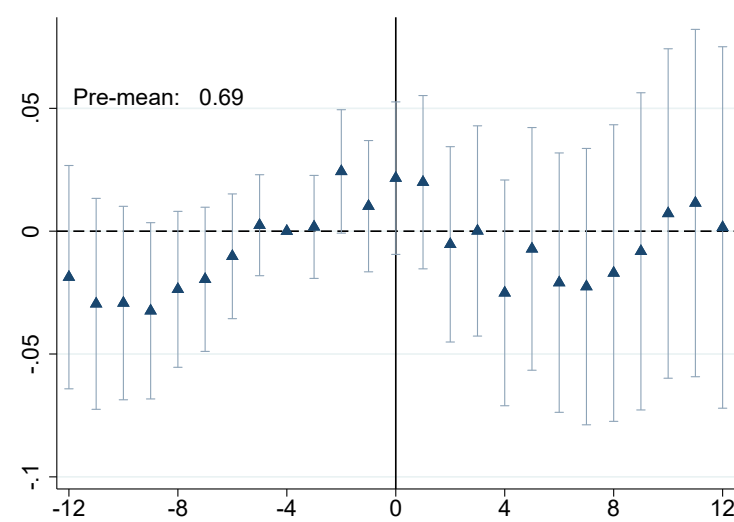

(a) Employment

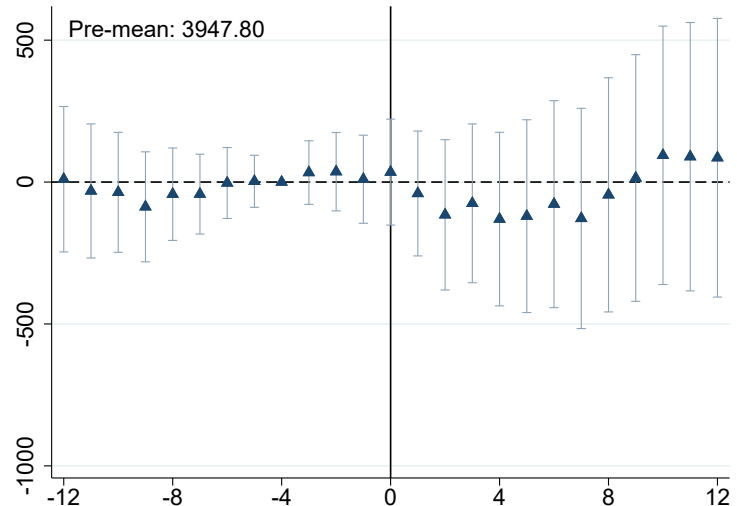

(b) Quarterly earnings in Euro

Notes: Each panel of the figure shows the event-study coefficients estimated from equation (1), including 95 percent confidence intervals of a fatal parental shock on the labor market outcome of the child. Standard errors are clustered at the individual level Pre-mean refers to the mean of the respective outcome variable four quarters prior to the parental fatal shock.

Figure 7: Children with retired parent: Impact of parental stroke on children's labor market outcomes

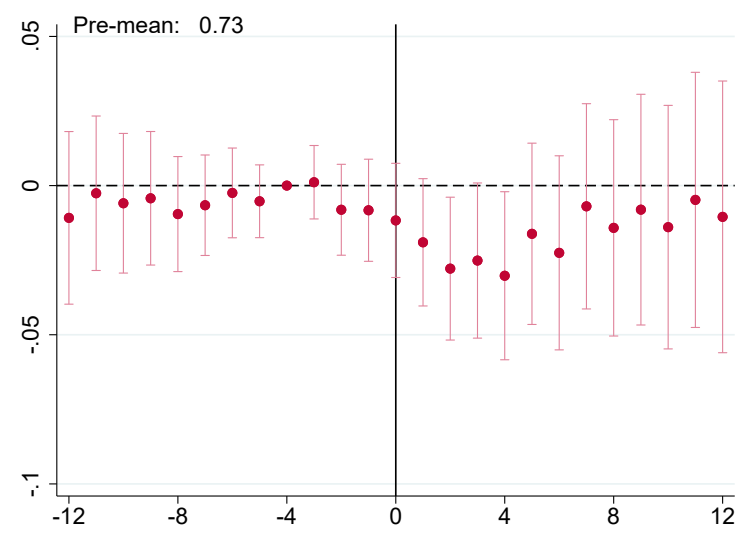

(a) Employment

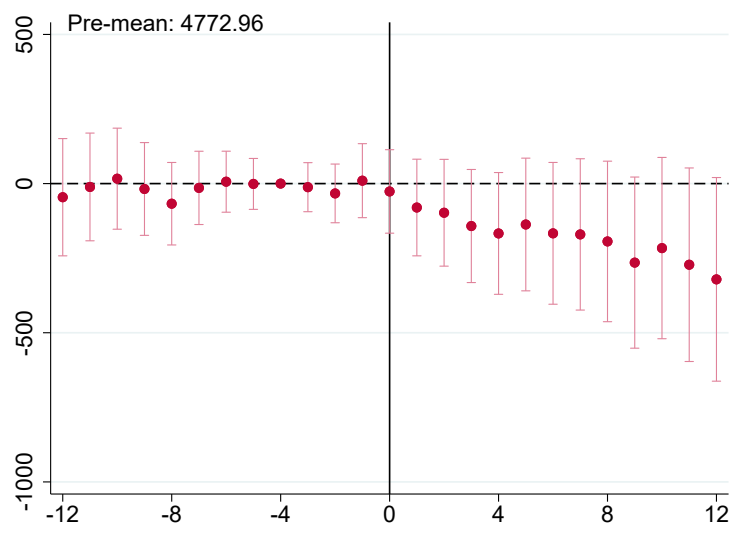

(b) Quarterly earnings of daughters in Euro

Notes: Each panel of the figure shows the event-study coefficients estimated from equation 1 (including 95 percent confidence intervals) of the parental stroke on the respective labor market outcome of the child. Standard errors are clustered at the individual level. Pre-mean refers to the mean of the respective outcome variable four quarters prior to the parental stroke. 
Figure 8: Impact of parental stroke on children's health outcomes

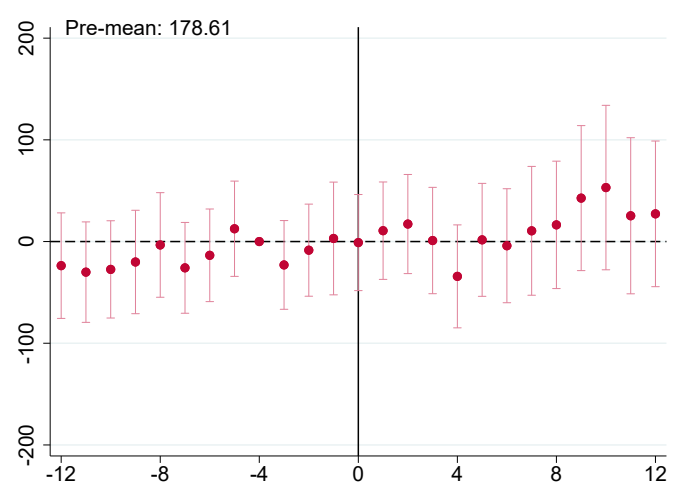

(a) Total health spending in Euro

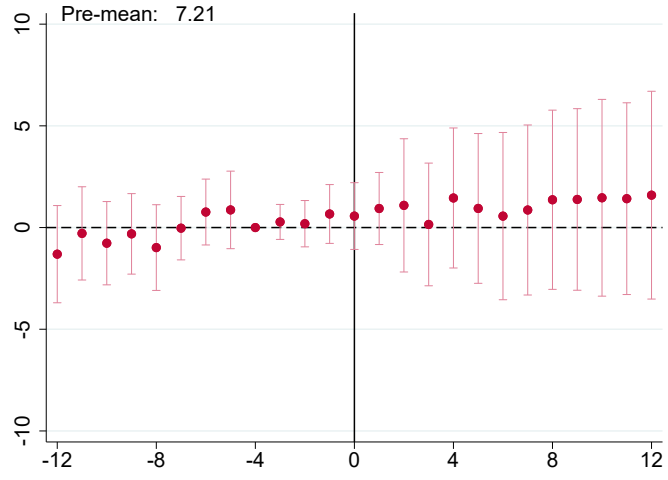

(b) Spending related to nerve system

Notes: Each panel of the figure shows the event-study coefficients estimated from equation (1), including 95 percent confidence intervals of the parental stroke on the respective health outcome of the child. Standard errors are clustered at the individual level. Pre-mean refers to the mean of the respective outcome variable four quarters prior to the parental stroke. 
Figure 9: Number of female care workers in Austria

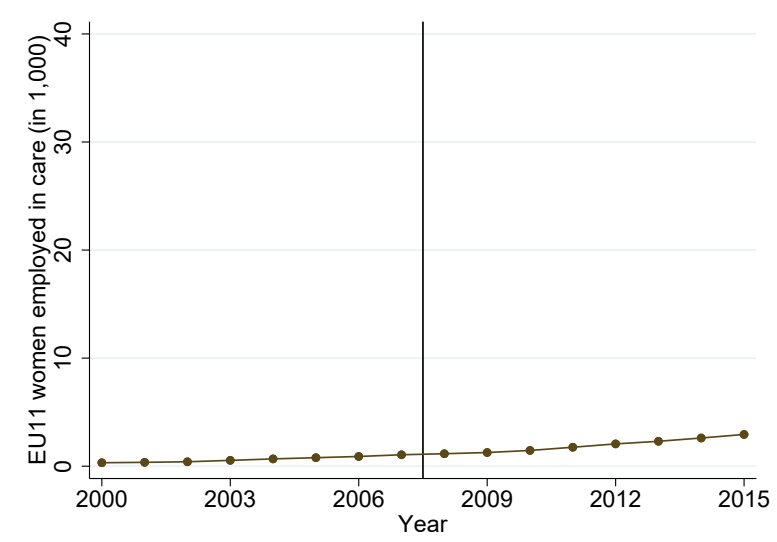

(a) EU11 women employed in care

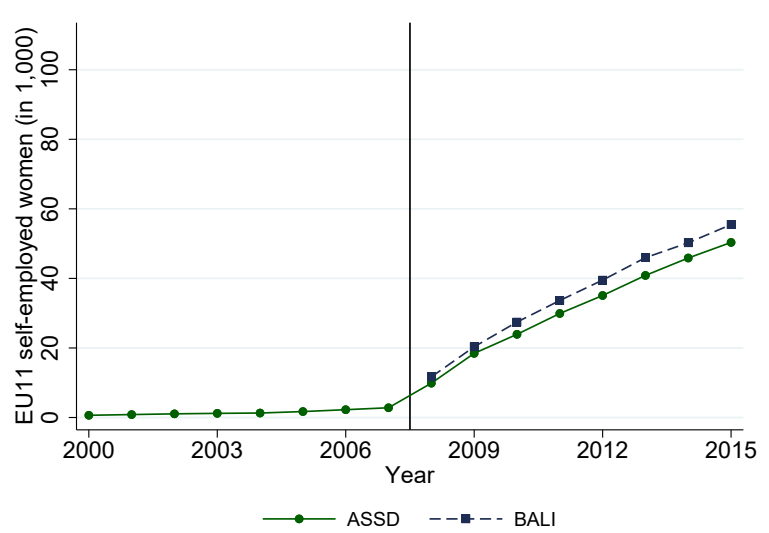

(c) EU11 self-employed women

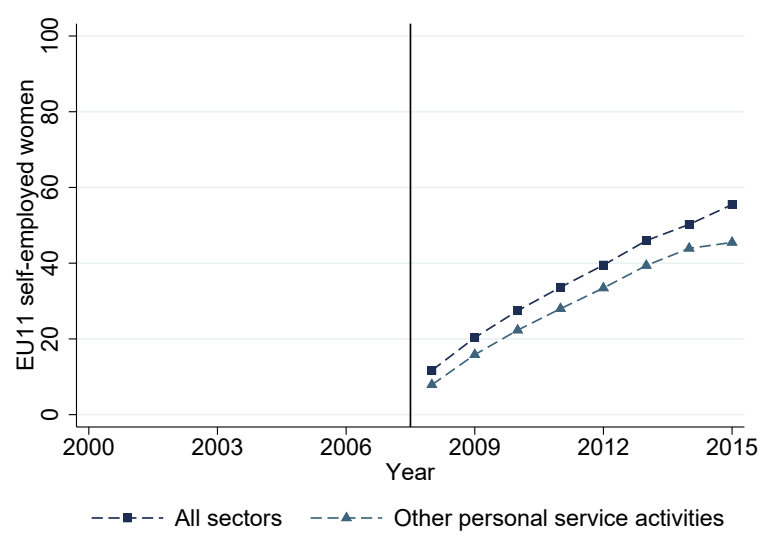

(e) EU11 self-employed women by sector

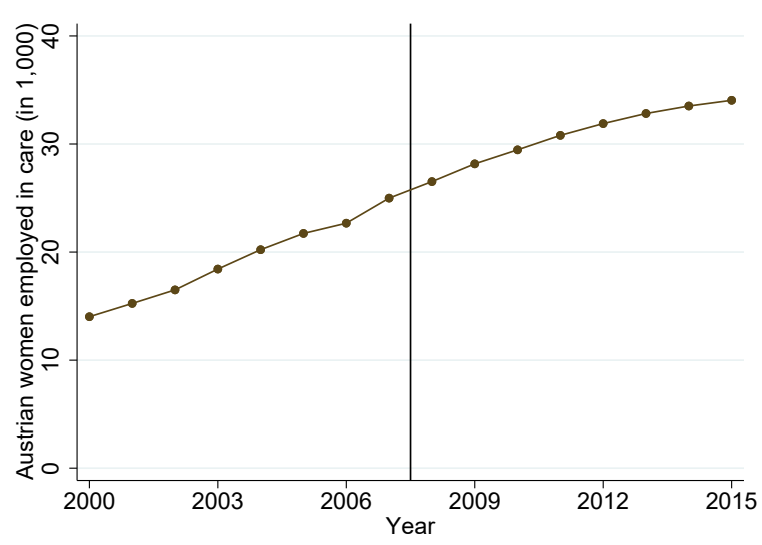

(b) Austrian women employed in care

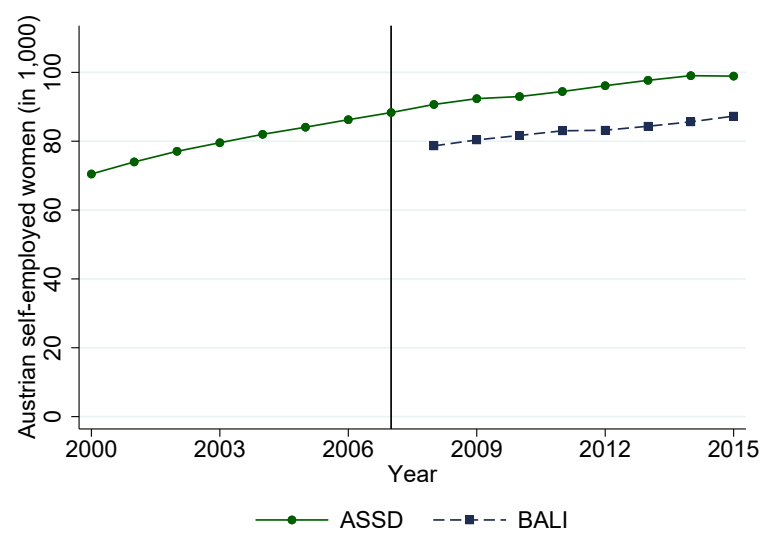

(d) Austrian self-employed women

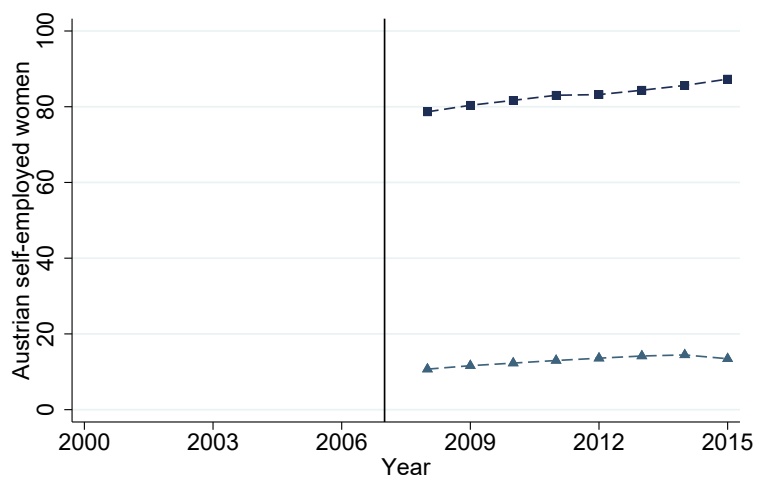

- - - - All sectors _ - $\$$ - Other personal service activities

(f) Austrian self-employed women by sector

Notes: The panels of this figure show the average number of female care workers in Austria from 2000 to 2015. For each year we take the average over the total number employed at four reference dates. The panels to the left (to the right) refer to EU11 nationals (Austrians). Panels a) and b) include all employees in the NACE categories 8710 (residential nursing care activities), 8730 (residential care activities for the elderly and disabled), 8790 (other residential care activities), and 8810 (social work activities without accommodation for the elderly and disabled). Panels c) and d) include all self-employed women from two different data sources. Panels e) and f) distinguish between all self-employed women and those in "Other personal service activities" based on the data. Source: Austrian Social Security Data, BALI (budget, labour market and benefit receipt information) online database. 
Figure 10: Annual income of dependent vs. self-employed care workers

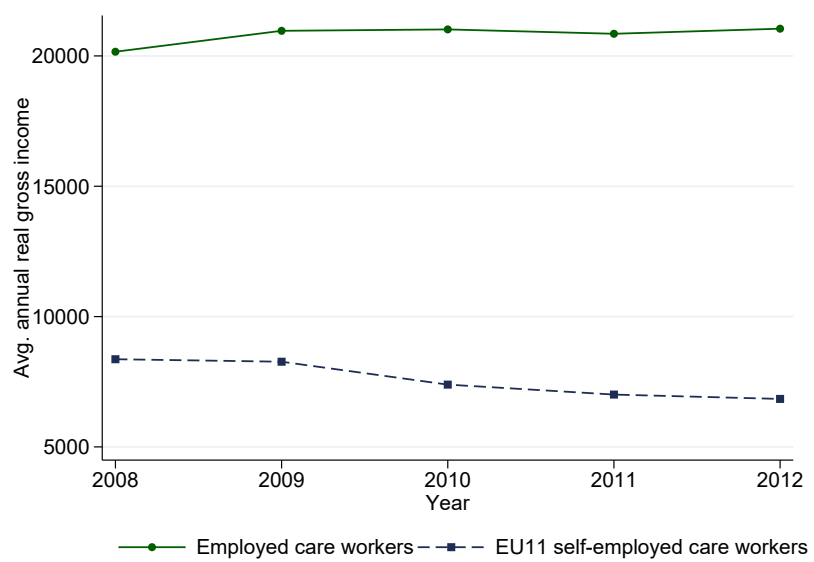

Notes: This figure shows the average annual gross income of the EU-11 self-employed female care workers as well as the average annual gross earnings of dependent female care workers in Austria. Dependent female care workers include all employees in the 4-digit NACE categories 8710 (residential nursing care activities), 8730 (residential care activities for the elderly and disabled), 8790 (other residential care activities), and 8810 (social work activities without accommodation for the elderly and disabled). Source: Austrian Social Security Data \& Austrian Tax Return Data. 


\section{Tables (to be placed in the article)}

Table 1: Descriptive statistics of analysis sample prior the shock

\begin{tabular}{|c|c|c|c|c|c|c|}
\hline \multirow[b]{2}{*}{ Variable } & \multicolumn{3}{|c|}{$\begin{array}{l}\text { Parent has stroke } \\
\qquad(N=2,763)\end{array}$} & \multicolumn{3}{|c|}{$\begin{array}{c}\text { Parent has heart attack } \\
\qquad(N=3,437)\end{array}$} \\
\hline & Treated & Spouse & Child & Treated & Spouse & Child \\
\hline Age & 61.09 & 58.81 & 30.12 & 58.65 & 56.51 & 29.10 \\
\hline Female & 0.32 & 0.70 & 0.48 & 0.24 & 0.77 & 0.48 \\
\hline Care allowance & 0.06 & 0.02 & - & 0.02 & 0.02 & - \\
\hline \multicolumn{7}{|l|}{ Labor market outcomes: } \\
\hline Employed & 0.38 & 0.38 & 0.72 & 0.51 & 0.46 & 0.73 \\
\hline Earnings & 2,597 & 2,011 & 4,535 & 3,755 & 2,334 & 4,446 \\
\hline \multicolumn{7}{|l|}{ Health outcomes: } \\
\hline Days in hospital & 1.33 & 0.61 & 0.30 & 0.76 & 0.59 & 0.38 \\
\hline Total health spendings & 689 & 415 & 178 & 575 & 406 & 188 \\
\hline Spendings medicine & 114 & 73 & 21 & 101 & 75 & 24 \\
\hline Observations & 2,763 & 2,603 & 4,206 & 3,437 & 3,295 & 5,201 \\
\hline
\end{tabular}

Notes: This table presents (quarterly) means of key variables in our analysis sample. The values reported in the table are based on data from four quarters before the health shock. All monetary values in the table are expressed in real $2010 \mathrm{Eu}-$ ros. Please note that data on care allowance receipt is only available until 2012, and some health care records only start in 2005 . 
Table 2: Impact of parental strokes on children's labor market outcomes

\begin{tabular}{|c|c|c|c|c|}
\hline & $\begin{array}{c}\text { employed } \\
\text { (1) }\end{array}$ & $\begin{array}{l}\text { earnings } \\
(2)\end{array}$ & $\begin{array}{c}\text { employed } \\
\text { (3) }\end{array}$ & $\begin{array}{c}\text { earnings } \\
\text { (4) }\end{array}$ \\
\hline \multicolumn{5}{|l|}{ Pooled } \\
\hline$\overline{\kappa_{p o s t}}$ & $\begin{array}{l}-0.019^{*} \\
(0.011)\end{array}$ & $\begin{array}{c}-196.054^{* * *} \\
(74.152)\end{array}$ & & \\
\hline Pre-mean & 0.72 & 4,535 & & \\
\hline Observations & \multicolumn{2}{|c|}{143,156} & & \\
\hline \multicolumn{5}{|c|}{ By subgroups } \\
\hline \multicolumn{5}{|c|}{ a. By sex of the child } \\
\hline & \multicolumn{2}{|c|}{$\underline{\text { female }}$} & \multicolumn{2}{|c|}{$\underline{\text { male }}$} \\
\hline$\overline{\kappa_{p o s t}}$ & $\begin{array}{l}-0.023 \\
(0.018)\end{array}$ & $\begin{array}{c}-254.590^{* *} \\
(106.313)\end{array}$ & $\begin{array}{l}-0.015 \\
(0.012)\end{array}$ & $\begin{array}{c}-144.796 \\
(104.464)\end{array}$ \\
\hline Pre-mean & 0.66 & 3,283 & 0.77 & 5,704 \\
\hline Observations & \multicolumn{2}{|c|}{69,298} & \multicolumn{2}{|c|}{73,858} \\
\hline
\end{tabular}

b. By geographic distance between child and parent

\begin{tabular}{ccccc} 
& \multicolumn{2}{c}{ local } & \multicolumn{2}{c}{ distant } \\
$\overline{\kappa_{\text {post }}}$ & $-0.028^{*}$ & $-205.150^{*}$ & -0.004 & -107.963 \\
& $(0.015)$ & $(107.773)$ & $(0.020)$ & $(134.890)$ \\
e-mean & 0.73 & 4,631 & 0.69 & 4,326 \\
servations & \multicolumn{2}{c}{64,811} & \multicolumn{2}{c}{48,230}
\end{tabular}

c. By parental care allowance receipt

\begin{tabular}{ccccc} 
& \multicolumn{2}{c}{ no care allowance } & \multicolumn{2}{c}{ care allowance } \\
$\overline{\kappa_{\text {post }}}$ & -0.005 & $-260.716^{*}$ & -0.063 & -391.124 \\
& $(0.022)$ & $(147.658)$ & $(0.040)$ & $(299.487)$ \\
e-mean & 0.70 & 4,120 & 0.77 & 4,696 \\
Oservations & \multicolumn{2}{c}{43,990} & \multicolumn{2}{c}{11,072}
\end{tabular}

d. By year of parental health shock

\begin{tabular}{lcccc} 
& \multicolumn{2}{c}{2007 and before } & \multicolumn{3}{c}{ after 2007} \\
$\overline{\kappa_{\text {post }}}$ & -0.070 & $-655.055^{* *}$ & 0.020 & -130.723 \\
& $(0.044)$ & $(312.755)$ & $(0.026)$ & $(186.129)$ \\
-mean & 0.72 & 4,086 & 0.72 & 4,574 \\
ervations & \multicolumn{2}{c}{19,734} & \multicolumn{2}{c}{46,259} \\
\hline
\end{tabular}

Notes: This table shows the impact of parental strokes on children's labor market outcomes by subgroups. $\overline{\kappa_{\text {post }}}$ measures the average over $\kappa_{k}$ for $k \geq 0$. The dependent variable in columns (1) and (3) is equal to one if the child is employed in a given quarter. In columns (2) and (4), the outcome is the quarterly earnings of the child in Euro. Pre-mean refers to the mean of the respective outcome variable four quarters prior to the shock. Standard errors are clustered at the individual level and reported in parentheses.

Geographic distance between parent and child in b. is defined as local if they live in the same municipality one year prior to the stroke and as distant otherwise. Geographic distance is missing for some children for whom we do not observe either their own or their parents' location. Parental care allowance receipt in c. is measured one year after the shock. Since data on care allowance receipt is only available until 2012, we restrict our analysis to years prior 2012. 2007 and before in d. refers to the years from 2003 to 2007, after 2007 to the years from 2008 to 2012. 
Table 3: DDD - Children's labor market outcomes

\begin{tabular}{|c|c|c|c|c|}
\hline & \multicolumn{2}{|c|}{ All } & \multicolumn{2}{|c|}{$\mathrm{W} / \mathrm{O}$ late controls } \\
\hline & $\begin{array}{c}\text { employed } \\
\text { (1) }\end{array}$ & $\begin{array}{l}\text { earnings } \\
(2)\end{array}$ & $\begin{array}{l}\text { employed } \\
\text { (3) }\end{array}$ & $\begin{array}{l}\text { earnings } \\
\text { (4) }\end{array}$ \\
\hline \multicolumn{5}{|c|}{ A: Five-year window around the reform } \\
\hline$\eta$ & $\begin{array}{l}0.036^{*} \\
(0.021)\end{array}$ & $\begin{array}{c}157.823 \\
(164.952)\end{array}$ & $\begin{array}{c}0.062^{* *} \\
(0.030)\end{array}$ & $\begin{array}{l}373.221^{*} \\
(215.188)\end{array}$ \\
\hline Observations & 100,725 & 100,725 & 81,200 & 81,200 \\
\hline \multicolumn{5}{|c|}{ B: Four-year window around the reform } \\
\hline$\eta$ & $\begin{array}{l}0.042^{*} \\
(0.024)\end{array}$ & $\begin{array}{c}212.236 \\
(184.483)\end{array}$ & $\begin{array}{c}0.077^{* *} \\
(0.039)\end{array}$ & $\begin{array}{l}458.129^{*} \\
(269.607)\end{array}$ \\
\hline Observations & 76,900 & 76,900 & 57,375 & 57,375 \\
\hline
\end{tabular}

Notes: This table displays the estimated coefficient on the triple interaction

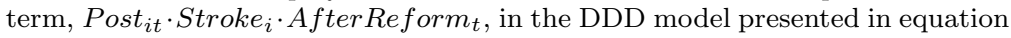
(2). The dependent variable in columns (1) and (3) is equal to one if the child is employed in a given quarter. In columns (2) and (4), the outcome is the quarterly earnings of the child in Euro. Standard errors are clustered at the individual level and reported in parentheses. ${ }^{*},{ }^{* *}$ and ${ }^{* * *}$ indicate significance at 10-, 5- and 1-percent levels, respectively. 


\section{Web appendix}

This Web appendix provides additional material discussed in the unpublished manuscript "Health of Elderly Parents, their Children's Labor Supply, and the Role of Migrant Care Workers" by Wolfgang Frimmel, Martin Halla, Jörg Paetzold, and Julia Schmieder. 


\section{A.1 Additional figures and tables}

Figure A.1: Impact of parental stroke on children's labor market outcomes by sex

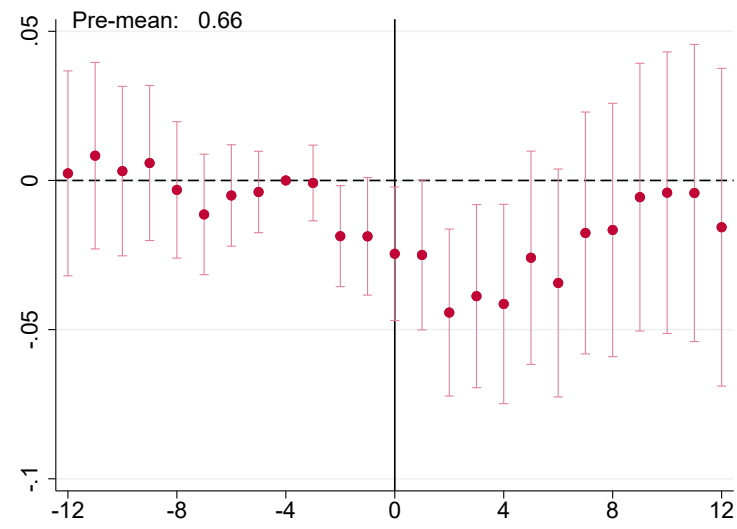

(a) Employment of daughters

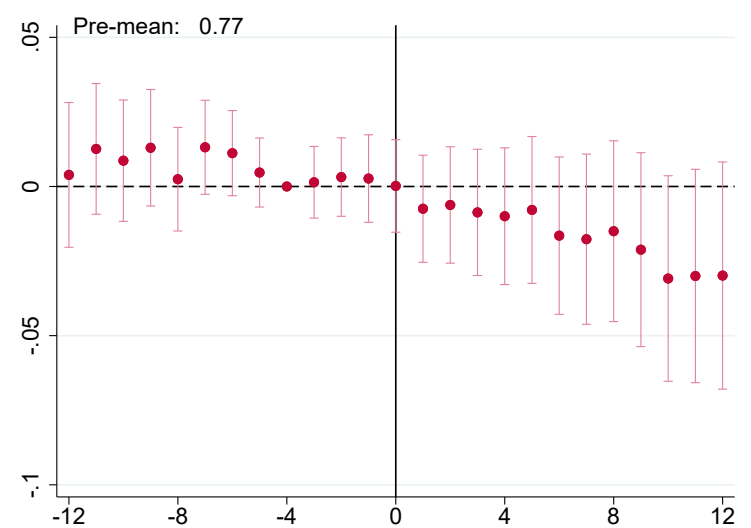

(c) Employment of sons

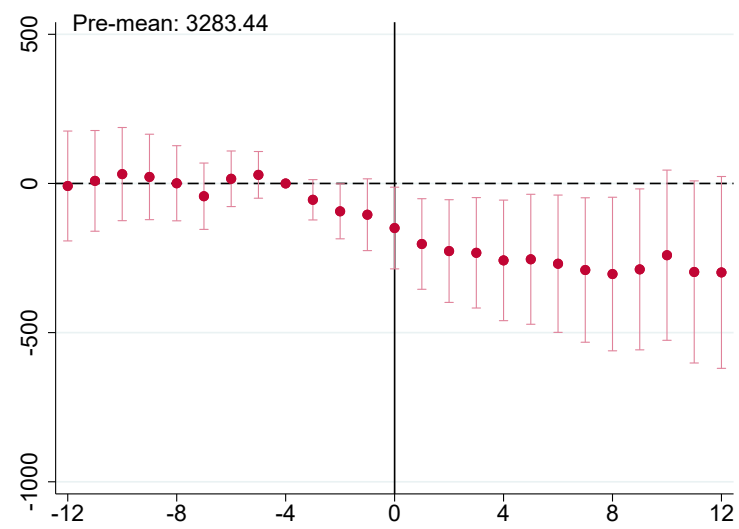

(b) Quarterly earnings of daughters in Euro

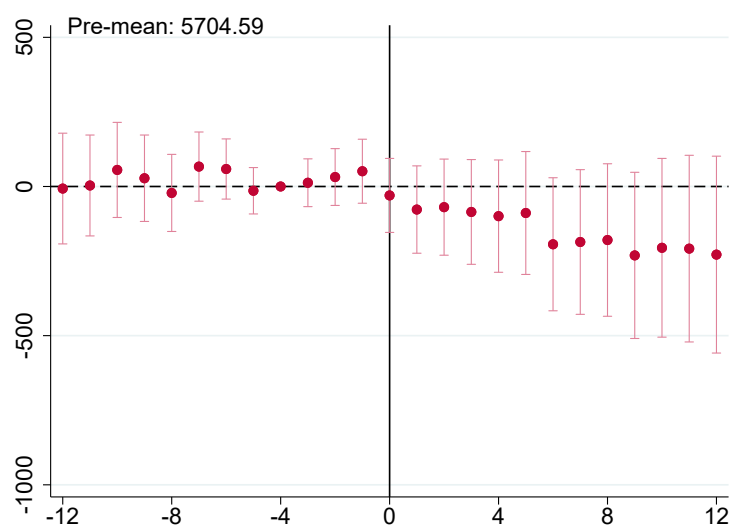

(d) Quarterly earnings of sons in Euro

Notes: Each panel of the figure shows the event-study coefficients estimated from equation 1 (including 95 percent confidence intervals) of the parental stroke on the respective labor market outcome of the child. Standard errors are clustered at the individual level. Pre-mean refers to the mean of the respective outcome variable four quarters prior to the parental stroke. 
Table A.1: Cash benefits of care allowance scheme in 2016

\begin{tabular}{cccc}
\hline (1) & $\begin{array}{c}(2) \\
\text { Care requirements } \\
\text { in hours per month }\end{array}$ & $\begin{array}{c}(3) \\
\text { Benefit } \\
\text { in Euro* }\end{array}$ & $\begin{array}{c}(4) \\
\text { Share of total } \\
\text { recipients** }^{* *}\end{array}$ \\
\hline 1 & $65<x \leq 95$ hours & 150.30 & 0.26 \\
2 & $95<x \leq 120$ hours & 290.00 & 0.24 \\
3 & $120<x \leq 160$ hours & 451.80 & 0.18 \\
4 & $160<x \leq 180$ hours & 677.60 & 0.14 \\
5 & $>180$ hours and ${ }^{\dagger}$ & 920.30 & 0.11 \\
6 & $>180$ hours and ${ }^{\ddagger}$ & $1,285.20$ & 0.04 \\
7 & $>180$ hours and ${ }^{\#}$ & $1,688.90$ & 0.02 \\
\hline
\end{tabular}

\footnotetext{
${ }^{*}$ Per month for year $2016 .{ }^{\dagger}$ Extraordinary high level of care required. $\ddagger$ Timely unpredictable care measures during day and night, or constant presence of carer required because person would be at risk. \# No goal-directed movements of the person's four extremities or equivalent condition. ${ }^{* *}$ The total number of recipients was 455,354, Source: Statistik Austria.
} 
Table A.2: Socio-economic determinants of informal care provision

\begin{tabular}{|c|c|c|c|}
\hline & $\begin{array}{l}(1) \\
\text { Hours }>0 \\
\text { OLS }\end{array}$ & $\begin{array}{c}(2) \\
\text { Hours/week } \\
\text { Tobit }\end{array}$ & $\begin{array}{c}(3) \\
\text { Hours/week } \\
\text { Truncated reg. }\end{array}$ \\
\hline \multicolumn{4}{|l|}{ Sex (Base group: male) } \\
\hline Female & $\begin{array}{l}0.018^{* * *} \\
(0.003)\end{array}$ & $\begin{array}{l}9.718^{* * *} \\
(1.859)\end{array}$ & $\begin{array}{c}7.606 \\
(13.408)\end{array}$ \\
\hline \multicolumn{4}{|c|}{ Age (Base group: below 25 years of age) } \\
\hline $25-39$ & $\begin{array}{c}0.009^{* *} \\
(0.004)\end{array}$ & $\begin{array}{r}7.755^{*} \\
(4.429)\end{array}$ & $\begin{array}{c}35.512 \\
(52.925)\end{array}$ \\
\hline $40-54$ & $\begin{array}{l}0.023^{* * *} \\
(0.005)\end{array}$ & $\begin{array}{l}15.319^{* * *} \\
(4.262)\end{array}$ & $\begin{array}{c}39.449 \\
(52.322)\end{array}$ \\
\hline$\geq 55$ & $\begin{array}{l}0.028^{* * *} \\
(0.004)\end{array}$ & $\begin{array}{l}17.381^{* * *} \\
(4.182)\end{array}$ & $\begin{array}{c}40.636 \\
(52.276)\end{array}$ \\
\hline \multicolumn{4}{|c|}{ Education (Base group: compulsory education) } \\
\hline Apprenticeship & $\begin{array}{r}-0.005 \\
(0.005)\end{array}$ & $\begin{array}{c}-0.832 \\
(2.039)\end{array}$ & $\begin{array}{l}-5.618 \\
(12.461)\end{array}$ \\
\hline Upper secondary & $\begin{array}{l}-0.005 \\
(0.005)\end{array}$ & $\begin{array}{c}-1.946 \\
(2.120)\end{array}$ & $\begin{array}{c}-24.195 \\
(19.743)\end{array}$ \\
\hline Tertiary & $\begin{array}{r}-0.012^{*} \\
(0.007)\end{array}$ & $\begin{array}{r}-6.467^{*} \\
(3.575)\end{array}$ & $\begin{array}{r}-124.521 \\
(95.547)\end{array}$ \\
\hline Missing information & $\begin{array}{c}-0.008^{* *} \\
(0.004)\end{array}$ & $\begin{array}{c}-93.025 \\
(.)\end{array}$ & \\
\hline \multicolumn{4}{|c|}{ Urbanization (Base group: low population density) } \\
\hline Medium & $\begin{array}{r}-0.002 \\
(0.004)\end{array}$ & $\begin{array}{c}-0.551 \\
(1.786)\end{array}$ & $\begin{array}{l}-3.941 \\
(12.200)\end{array}$ \\
\hline High & $\begin{array}{c}-0.009^{* *} \\
(0.004)\end{array}$ & $\begin{array}{c}-4.639^{* *} \\
(2.079)\end{array}$ & $\begin{array}{c}6.326 \\
(13.681)\end{array}$ \\
\hline Constant & $\begin{array}{c}0.002 \\
(0.004)\end{array}$ & $\begin{array}{c}-65.696^{* * *} \\
(6.124)\end{array}$ & $\begin{array}{c}-78.081 \\
(78.654)\end{array}$ \\
\hline Number of observations & 8,234 & 8,234 & 184 \\
\hline $\begin{array}{l}\text { Mean of dependent variable } \\
\text { (Pseudo) R-squared }\end{array}$ & $\begin{array}{l}0.022 \\
0.011\end{array}$ & $\begin{array}{l}0.211 \\
0.037\end{array}$ & 9.435 \\
\hline
\end{tabular}

Notes: This table summarizes estimations of the socio-economic determinants of informal care provision in Austria based on data from the Austrian Time Use Survey (Zeitverwendungserhebung) 2008/2009. Further details on the data source are provided in (Statistik Austria 2009). In column (1), the sample comprises all individuals. The dependent variable is a binary indicator equal to one if the individual provides any informal care (hours $>0$ ) and zero otherwise. The method of estimation is OLS, and reported standard errors are robust to heteroskedasticity of unknown form. In column (2), the sample comprises all individuals. The dependent variable is equal to the number of hours of informal care individuals provide per week. To account for censoring of the dependent variable a Tobit model is used. In column (3), the sample comprises only the 184 individuals, who provide any informal care (hours $>0$ ). The dependent variable is equal to the number of hours of informal care individuals provide per week. To account for the truncated sample a truncated regression model is used. (Robust) standard errors are reported in parentheses. ${ }^{*},{ }^{* *}$ and ${ }^{* * *}$ indicate significance at 10-, 5- and 1-percent levels, respectively. 
Table A.3: Impact of parental stroke on further labor market outcomes of the children

\begin{tabular}{lccc}
\hline & $\begin{array}{c}\text { days } \\
\text { employed } \\
(1)\end{array}$ & $\begin{array}{c}\text { daily } \\
\text { wage } \\
(2)\end{array}$ & $\begin{array}{c}\text { full-time } \\
\text { employed } \\
(3)\end{array}$ \\
\hline$\overline{\kappa_{\text {post }}}$ & $-1.852^{* *}$ & $-1.846^{* *}$ & $-0.024^{*}$ \\
& $(0.922)$ & $(0.803)$ & $(0.013)$ \\
Pre-mean & 66.4 & 52.9 & 0.80 \\
\hline Observations & \multicolumn{2}{c}{136,129} & 61,346
\end{tabular}

Notes: This table shows the impact of parental strokes on additional labor market outcomes of children. $\overline{\kappa_{\text {post }}}$ measures the average over $\kappa_{k}$ for $k \geq 0$. The dependent variable in column (1) is the number of days employed per quarter, in (2) the daily wage in euro, and in (3) an indicator for full-time employment. Pre-mean refers to the mean in the respective outcome one year prior to the shock. Standard errors are clustered at the individual level and reported in parentheses. ${ }^{*},{ }^{* *}$ and ${ }^{* * *}$ indicate significance at 10-, 5- and 1-percent levels, respectively. 
Table A.4: DDD - Children's labor market outcomes

\begin{tabular}{|c|c|c|c|c|}
\hline & \multicolumn{2}{|c|}{ All } & \multicolumn{2}{|c|}{$\mathrm{W} / \mathrm{O}$ late controls } \\
\hline & $\begin{array}{c}\text { employed } \\
\text { (1) }\end{array}$ & $\begin{array}{c}\text { earnings } \\
(2)\end{array}$ & $\begin{array}{c}\text { employed } \\
(3)\end{array}$ & $\begin{array}{c}\text { earnings } \\
(4)\end{array}$ \\
\hline \multicolumn{5}{|c|}{ A: Five-year window around the reform } \\
\hline$\gamma_{1}:$ Post & $\begin{array}{c}-0.002 \\
(0.016)\end{array}$ & $\begin{array}{c}-72.999 \\
(132.693)\end{array}$ & $\begin{array}{l}0.058^{*} \\
(0.034)\end{array}$ & $\begin{array}{l}446.594^{*} \\
(253.144)\end{array}$ \\
\hline$\gamma_{2}:$ Stroke & $\begin{array}{c}0.007 \\
(0.020)\end{array}$ & $\begin{array}{c}112.272 \\
(163.439)\end{array}$ & $\begin{array}{c}-0.009 \\
(0.032)\end{array}$ & $\begin{array}{c}124.254 \\
(237.873)\end{array}$ \\
\hline$\gamma_{3}:$ After 2007 & $\begin{array}{c}-0.023 \\
(0.023)\end{array}$ & $\begin{array}{c}-46.923 \\
(236.629)\end{array}$ & $\begin{array}{c}0.038 \\
(0.046)\end{array}$ & $\begin{array}{l}664.465^{*} \\
(376.678)\end{array}$ \\
\hline$\gamma_{4}:$ Post $\cdot$ Stroke & $\begin{array}{c}-0.039^{* *} \\
(0.018)\end{array}$ & $\begin{array}{c}-247.217^{*} \\
(140.204)\end{array}$ & $\begin{array}{c}-0.065^{* *} \\
(0.028)\end{array}$ & $\begin{array}{c}-463.537^{* *} \\
(196.702)\end{array}$ \\
\hline$\gamma_{5}:$ Post $\cdot$ After 2007 & $\begin{array}{c}0.004 \\
(0.020)\end{array}$ & $\begin{array}{c}52.984 \\
(170.114)\end{array}$ & $\begin{array}{l}-0.056 \\
(0.037)\end{array}$ & $\begin{array}{c}-457.262 \\
(285.250)\end{array}$ \\
\hline$\gamma_{6}:$ Stroke $\cdot$ After 2007 & $\begin{array}{l}-0.004 \\
(0.024)\end{array}$ & $\begin{array}{l}-118.561 \\
(216.788)\end{array}$ & $\begin{array}{c}0.012 \\
(0.035)\end{array}$ & $\begin{array}{c}-129.959 \\
(277.036)\end{array}$ \\
\hline$\eta$ & $\begin{array}{l}0.036^{*} \\
(0.021)\end{array}$ & $\begin{array}{c}157.823 \\
(164.952)\end{array}$ & $\begin{array}{c}0.062^{* *} \\
(0.030)\end{array}$ & $\begin{array}{l}373.221^{*} \\
(215.188)\end{array}$ \\
\hline Observations & 100,725 & 100,725 & 81,200 & 81,200 \\
\hline \multicolumn{5}{|c|}{ B: Four-year window around the reform } \\
\hline$\gamma_{1}:$ Post & $\begin{array}{c}-0.012 \\
(0.018)\end{array}$ & $\begin{array}{l}-127.267 \\
(148.596)\end{array}$ & $\begin{array}{c}0.070 \\
(0.045)\end{array}$ & $\begin{array}{l}768.479^{* *} \\
(355.497)\end{array}$ \\
\hline$\gamma_{2}:$ Stroke & $\begin{array}{c}0.010 \\
(0.022)\end{array}$ & $\begin{array}{c}142.753 \\
(181.790)\end{array}$ & $\begin{array}{l}-0.010 \\
(0.042)\end{array}$ & $\begin{array}{c}205.910 \\
(317.586)\end{array}$ \\
\hline$\gamma_{3}:$ After 2007 & $\begin{array}{l}-0.033 \\
(0.024)\end{array}$ & $\begin{array}{c}20.700 \\
(247.190)\end{array}$ & $\begin{array}{c}0.047 \\
(0.057)\end{array}$ & $\begin{array}{c}1105.460^{* *} \\
(455.391)\end{array}$ \\
\hline$\gamma_{4}:$ Post $\cdot$ Stroke & $\begin{array}{c}-0.039^{* *} \\
(0.019)\end{array}$ & $\begin{array}{c}-219.520 \\
(155.409)\end{array}$ & $\begin{array}{c}-0.074^{* *} \\
(0.036)\end{array}$ & $\begin{array}{c}-465.982^{*} \\
(250.524)\end{array}$ \\
\hline$\gamma_{5}:$ Post $\cdot$ After 2007 & $\begin{array}{c}0.017 \\
(0.021)\end{array}$ & $\begin{array}{c}46.650 \\
(185.129)\end{array}$ & $\begin{array}{l}-0.065 \\
(0.048)\end{array}$ & $\begin{array}{c}-834.137^{* *} \\
(391.781)\end{array}$ \\
\hline$\gamma_{6}:$ Stroke $\cdot$ After 2007 & $\begin{array}{l}-0.000 \\
(0.027)\end{array}$ & $\begin{array}{l}-314.672 \\
(244.143)\end{array}$ & $\begin{array}{c}0.020 \\
(0.045)\end{array}$ & $\begin{array}{c}-378.149 \\
(356.574)\end{array}$ \\
\hline$\eta$ & $\begin{array}{l}0.042^{*} \\
(0.024)\end{array}$ & $\begin{array}{c}212.236 \\
(184.483)\end{array}$ & $\begin{array}{c}0.077^{* *} \\
(0.039)\end{array}$ & $\begin{array}{l}458.129^{*} \\
(269.607)\end{array}$ \\
\hline Observations & 76,900 & 76,900 & 57,375 & 57,375 \\
\hline
\end{tabular}

Notes: This table displays the estimated coefficients for the DDD model presented in equation (2). The dependent variable in columns (1) and (3) is equal to one if the child is employed in a given quarter. In columns (2) and (4), the outcome is the quarterly earnings of the child in Euro. Standard errors are clustered at the individual level and reported in parentheses. ${ }^{*},{ }^{* *}$ and ${ }^{* * *}$ indicate significance at $10-, 5$ - and 1-percent levels, respectively. 


\section{A.2 Spouses after partner's stroke}

In this section, we study the impact of the health shock on spousal labor supply. We will focus on strokes, since those have been found to cause large increases in care dependency

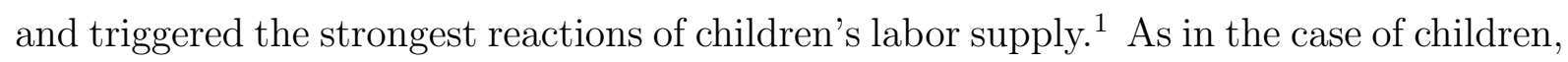
we will study labor market outcomes of the spouse three years before and after the stroke. Figure A.2 displays event-study coefficients and standard errors estimated from equation 1 for employment and quarterly earnings. As it can be seen from the figure, for none of the labor market outcomes we find significant effects. Given the very low labor market attachment of the spouse prior to the shock (employment rates are around 38 percent, see Table 1), this results seems not surprising. Furthermore, it is a priori unclear whether a spouse reacts to such a shock with decreasing labor supply in order to provide informal care, or with an increase of labor supply (to compensate for the household income shock, or to raise financial resources to buy formal care). Overall, the results of Figure A.2 are in line with the findings of Fadlon and Nielsen (2020), which do not observe any economically meaningful effects of a non-fatal health shock on spousal labor supply.

Figure A.2: Spouse's labor market outcomes: Strokes

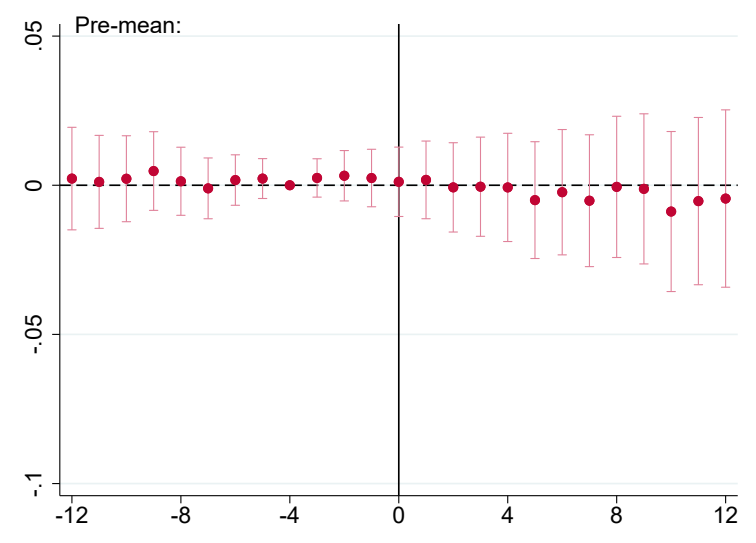

(a) Employment

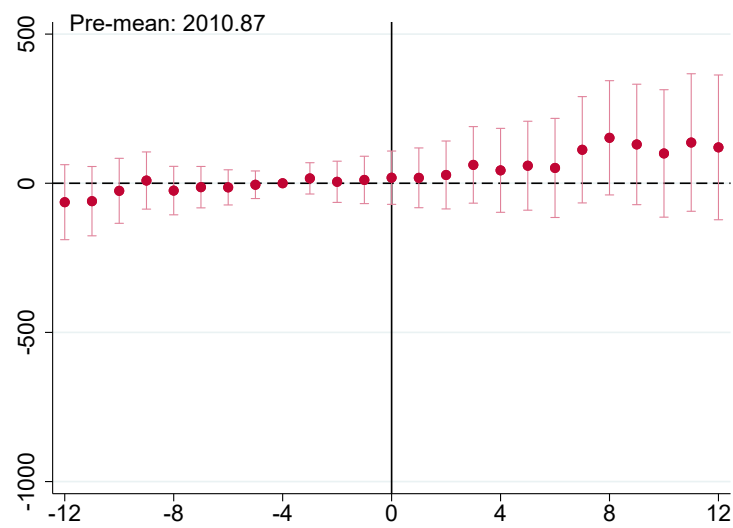

(b) Quarterly earnings in Euro B

Notes: Each panel of the figure shows the event-study coefficients estimated from equation 1 (including 95 percent confidence intervals) of a stroke on the labor market outcome of the spouse. Standard errors are clustered at the individual level. Pre-mean refers to the mean of the respective outcome variable four quarters prior to the parental stroke.

\footnotetext{
${ }^{1}$ The results are similar for heart attacks.
} 


\section{A.3 Sensitivity and robustness checks}

\section{A.3.1 Empirical approach with explicit control group}

Our event-study approach uses a varying control group over $k$, the quarters relative to the quarter of the shock (Druedahl and Martinello, 2016). As a robustness check, we implement the approach of Fadlon and Nielsen (2020, 2019) that relies on a fixed control group over $k$. More precisely, we compare the outcomes of individuals whose family experiences a parental health shock in time $\tau$ with those of families who experience the same shock twelve quarters in the future, i.e. in $\tau+12$.

Our strategy to construct the control group is as follows. We start with a cohort of individuals of the same birth cohort and define individuals from families experiencing a shock in a (reference) quarter $\tau$ as the treatment group. The control group is given by the set of individuals in the same birth cohort, whose families experience a parental health shock twelve quarters in the near future, in $\tau+12$. We then assign a placebo shock at $\tau$ to the individuals in the control group. It is important to hold the birth cohort of the treated and control group fixed to make sure that they are at the same stage of their life-cycle at date $h$. We repeat the construction of the control group for every combination of birth cohort and reference quarter $\tau$ and construct weights such that the treatment and control group size is balanced within each cell.

The reference date is such that for the treatment group it refers to the actual date of the shock, whereas for the control group it refers to the date of the placebo shock. Based on this treatment and control group, we estimate the dynamic difference-in-differences (DD) model:

$$
O_{i, t}=\theta D_{i}+\sum_{k=-12}^{11} \gamma_{k} I\left\{t-\tau_{i}=k\right\}+\sum_{\substack{k=-12 \\ k \neq-4}}^{11} \delta_{k} D_{i} * I\left\{t-\tau_{i}=k\right\}+\lambda_{t}+v_{i, t}
$$

where $O_{i t}$ is the outcome of individual $i$ in quarter $t, k$ measures the number of quarters relative to the reference quarter, $D_{i}$ is an indicator equal to one if the parent has a health shock at $k=0$ and equal to zero if the shock is at $k=12, I\{$.$\} is the indicator function,$ and $v_{i, t}$ is the error term. The parameter $\theta$ estimates the overall mean difference in the outcome between treated and controls, the parameters $\gamma_{k}$ measure the quarterly time profile of the outcome in the control group and $\delta_{k}$ measure the difference in time profiles between the treated and the control group relative to the reference quarter.

The results from this robustness check are illustrated in Appendix Figures A.3, A.4, A.5, and A.6. 
Figure A.3: Impact of parental stroke on parental health

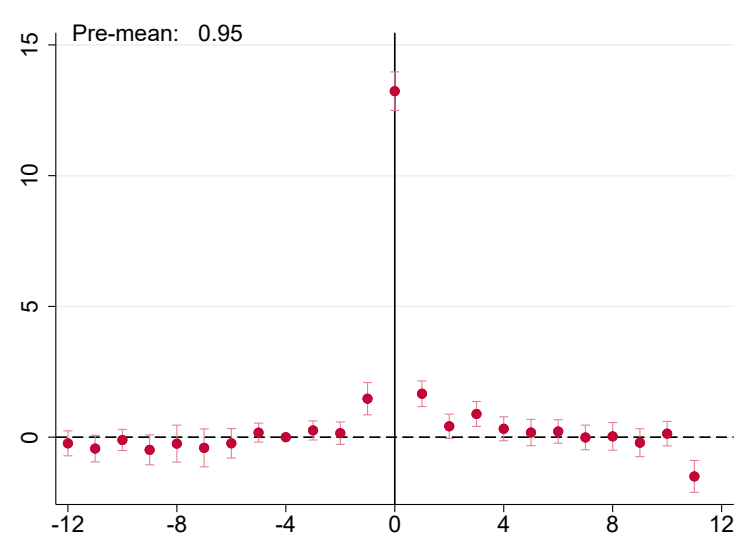

(a) Days in hospital

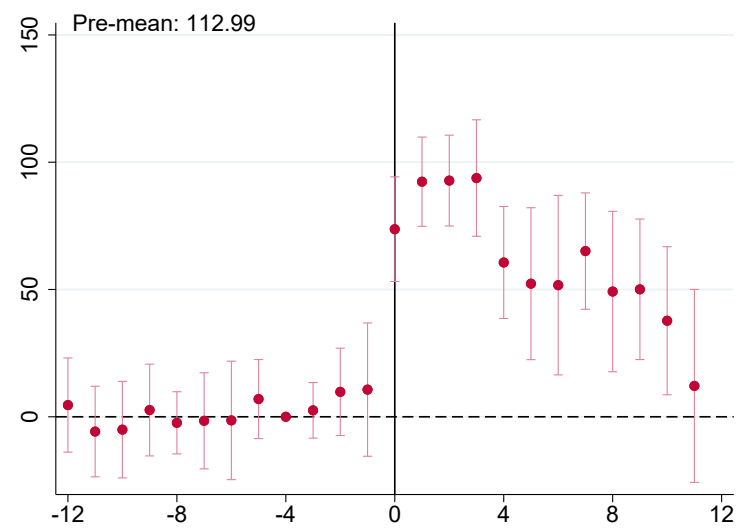

(c) Spendings on prescription drugs in Euro

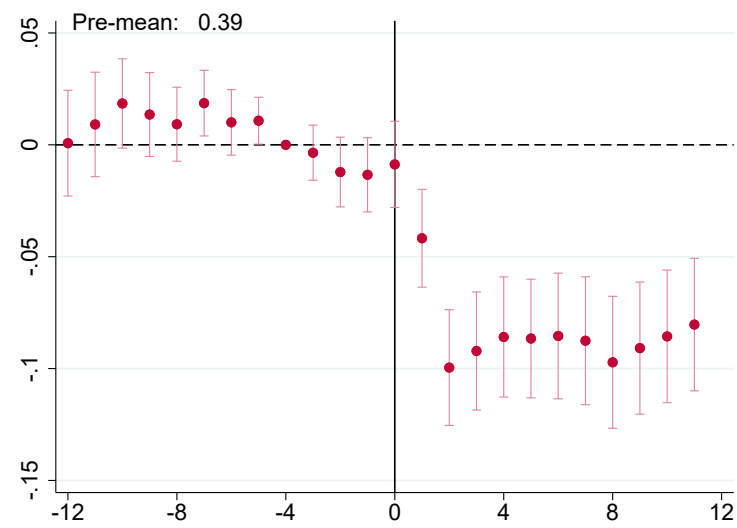

(e) Employment

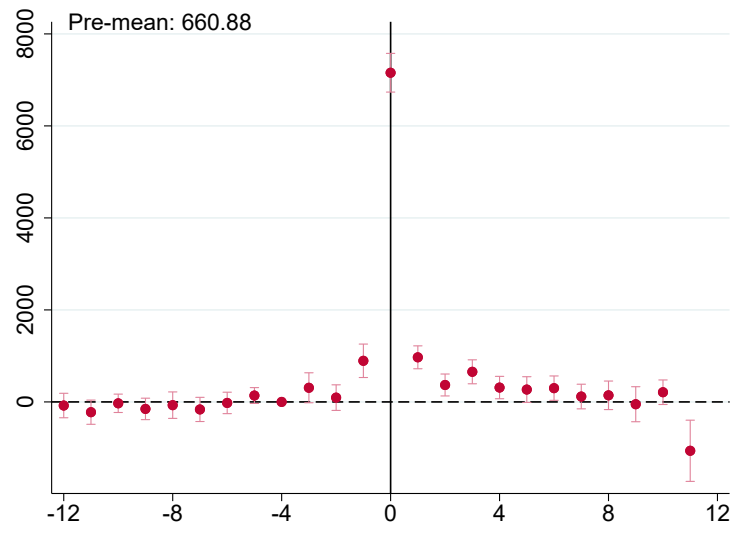

(b) Total health-care spendings in Euro

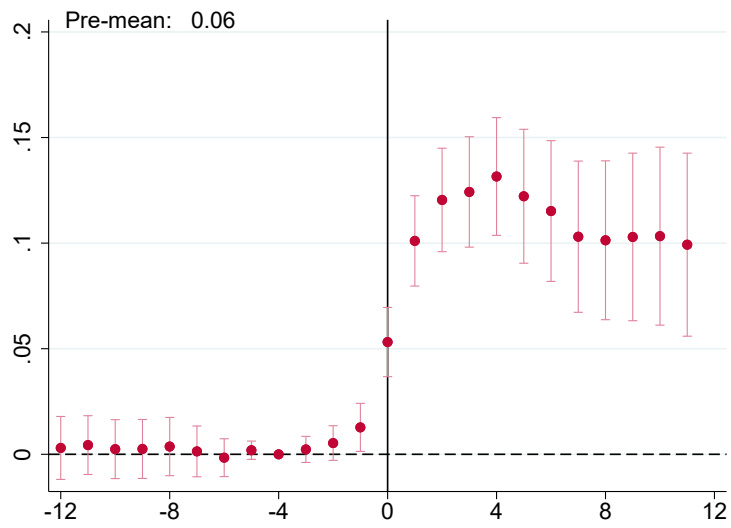

(d) Receipt of care allowance $(0 / 1)$

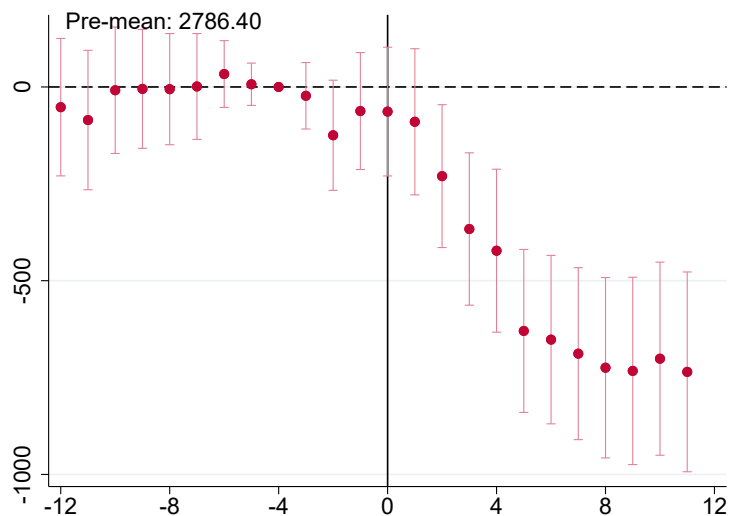

(f) Quarterly earnings in Euro

Notes: In each panel of the figure we compare the difference in parental outcomes between parents who have a health shock at the reference date and parents who have a health shock twelve quarters after the reference date. We assign a placebo shock to the later group at the reference date. The $\mathrm{x}$-axis denotes the quarters relative to the reference date. We normalize the difference between these two groups in -4 and control for time fixed effects. This approach is inspired by Fadlon and Nielsen (2019). We include 95 percent confidence intervals based on standard errors clustered at the individual level. Pre-mean refers to the mean of the respective outcome variable four quarters prior to the parental stroke. 
Figure A.4: Impact of parental stroke on children's labor market outcomes

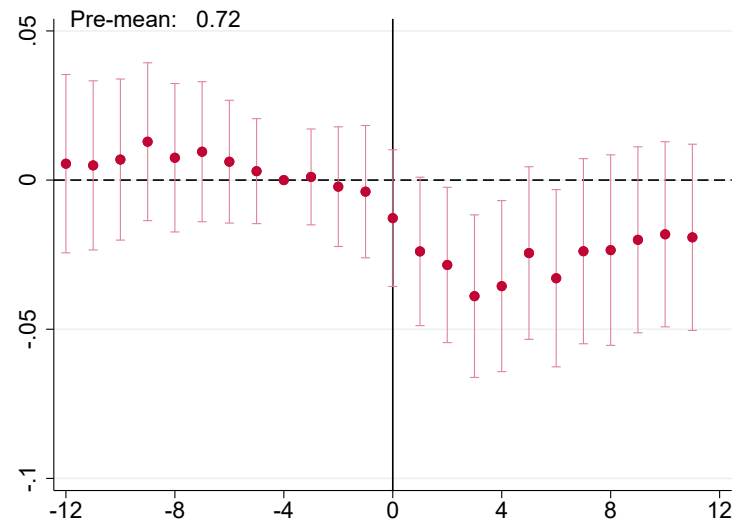

(a) Employment

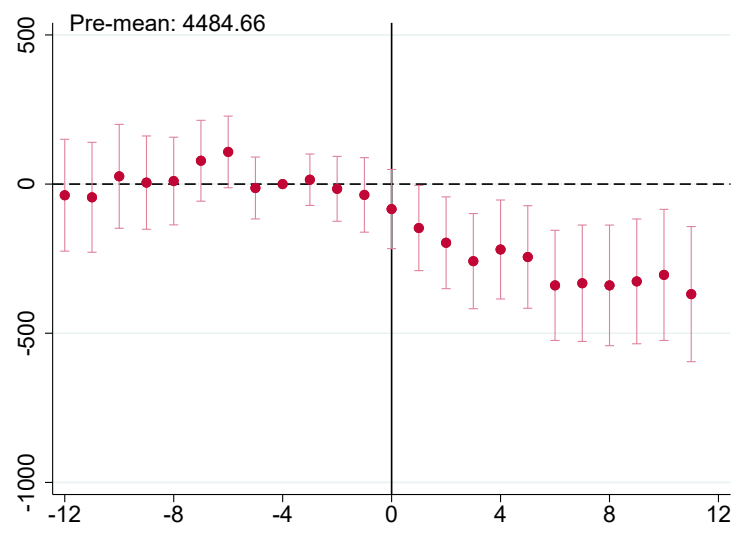

(b) Quarterly earnings in Euro

Notes: In each panel of the figure we compare the difference in children's outcomes between children who have parents with a health shock at the reference date and children who have parents with a health shock twelve quarters after the reference date. We assign a placebo shock to the later group at the reference date. The $\mathrm{x}$-axis denotes the quarters relative to the reference date. We normalize the difference between these two groups in -4 and control for time fixed effects. This approach is inspired by Fadlon and Nielsen (2019). We include 95 percent confidence intervals based on standard errors clustered at the individual level. Pre-mean refers to the mean of the respective outcome variable four quarters prior to the parental stroke. 
Figure A.5: Impact of parental heart attack on parental health

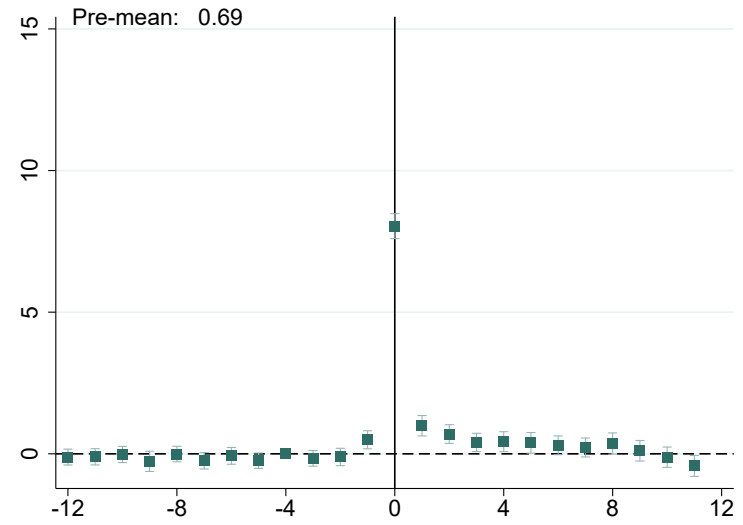

(a) Days in hospital

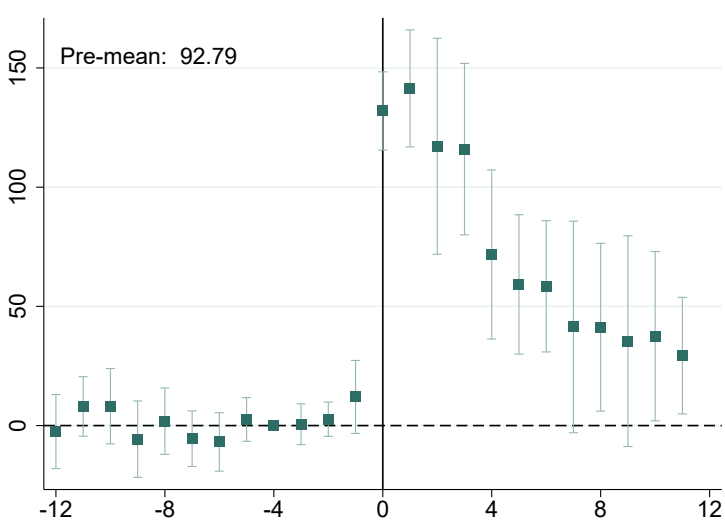

(c) Spendings on prescription drugs in Euro

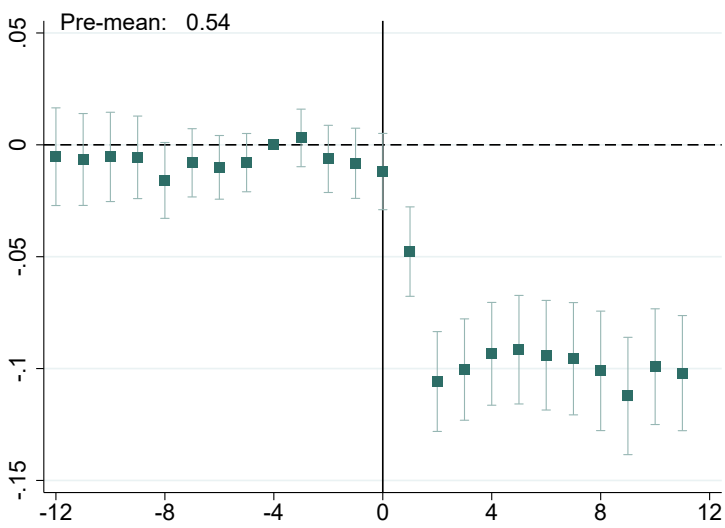

(e) Employment

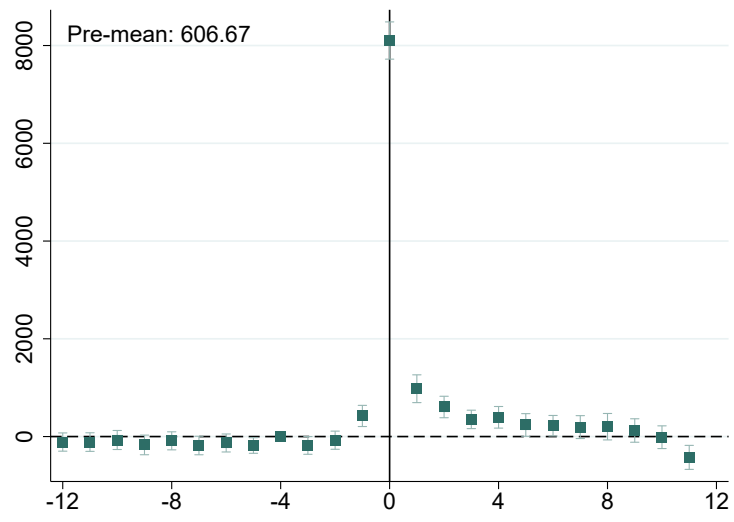

(b) Total health-care spendings in Euro

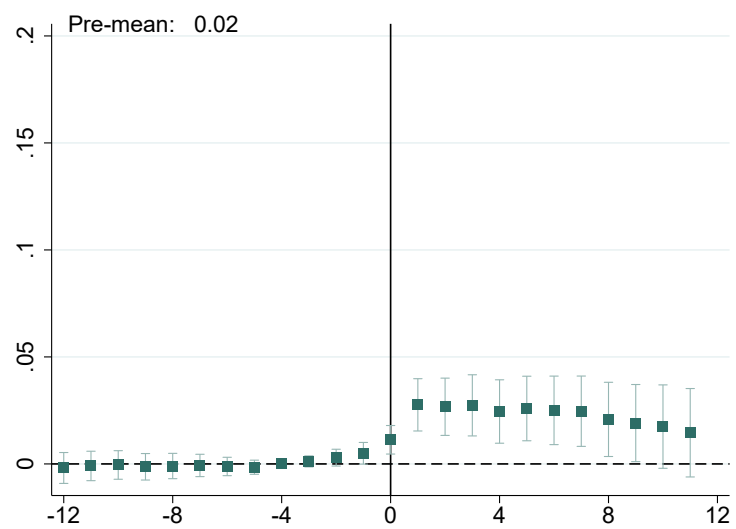

(d) Receipt of care allowance $(0 / 1)$

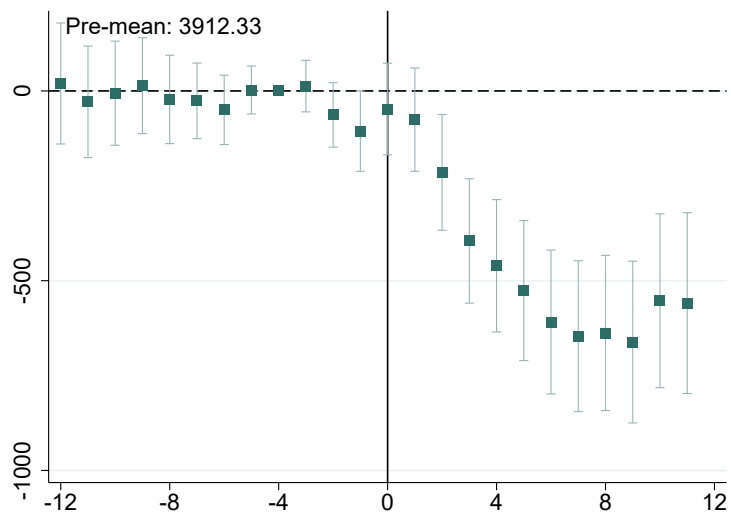

(f) Quarterly earnings in Euro

Notes: In each panel of the figure we compare the difference in parental outcomes between parents who have a health shock at the reference date and parents who have a health shock twelve quarters after the reference date. We assign a placebo shock to the later group at the reference date. The $\mathrm{x}$-axis denotes the quarters relative to the reference date. We normalize the difference between these two groups in -4 and control for time fixed effects. This approach is inspired by Fadlon and Nielsen (2019). We include 95 percent confidence intervals based on standard errors clustered at the individual level. Pre-mean refers to the mean of the respective outcome variable four quarters prior to the parental stroke. 
Figure A.6: Impact of parental heart attack on children's labor market outcomes

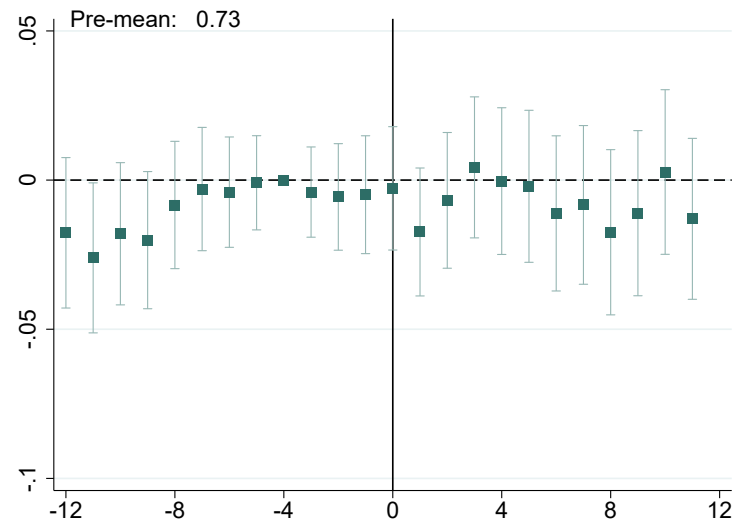

(a) Employment

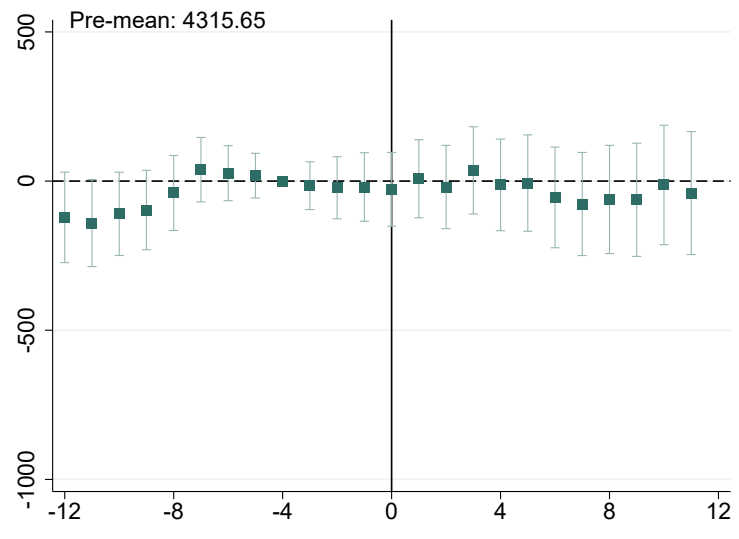

(b) Quarterly earnings in Euro

Notes: In each panel of the figure we compare the difference in children's outcomes between children who have parents with a health shock at the reference date and children who have parents with a health shock twelve quarters after the reference date. We assign a placebo shock to the later group at the reference date. The $\mathrm{x}$-axis denotes the quarters relative to the reference date. We normalize the difference between these two groups in -4 and control for time fixed effects. This approach is inspired by Fadlon and Nielsen (2019). We include 95 percent confidence intervals based on standard errors clustered at the individual level. Pre-mean refers to the mean of the respective outcome variable four quarters prior to the parental stroke. 


\section{A.3.2 Excluding cases where the affected parent dies within three years}

As described in Section 3.2, in our baseline sample we employ all parental strokes and heart attacks where the affected parent survives at least the first week after the health shock. In the following, we show that our results do not qualitatively change when using a more restrictive sample definition. Specifically, we now keep only parent-child pairs where the affected parent survives over the entire time horizon of our analysis (survival $\geq 3$ years). It is important to note that only around $10 \%$ of the affected parents in our baseline sample are dropped when introducing this restriction. This has to do with the fact that we focus on the first parental stroke (or heart attack) in our baseline sample. As a result, affected parents in our baseline sample are relatively young (around 60 years old) and, thus, the survival rates are quite high.

Appendix Figures A.7 and A.8 replicate our baseline results in Figures 2 and 4 but using this more restrictive sample. In sum, our baseline results remain primarily unchanged. Specifically, we find significant negative effects on employment as well as earnings of children. The magnitude of the effects is similar to our baseline sample. In sum, we find that restricting our analysis to parents who survive over the entire time horizon does not change our conclusions, which is not surprising given that $90 \%$ of cases in our baseline fulfill this requirement. However, in order to fully exploit all parent-child-quarter combinations in our data, we decided to keep the unrestricted sample as our baseline. 
Figure A.7: Impact of parental stroke on parental health - Families with surviving parents only

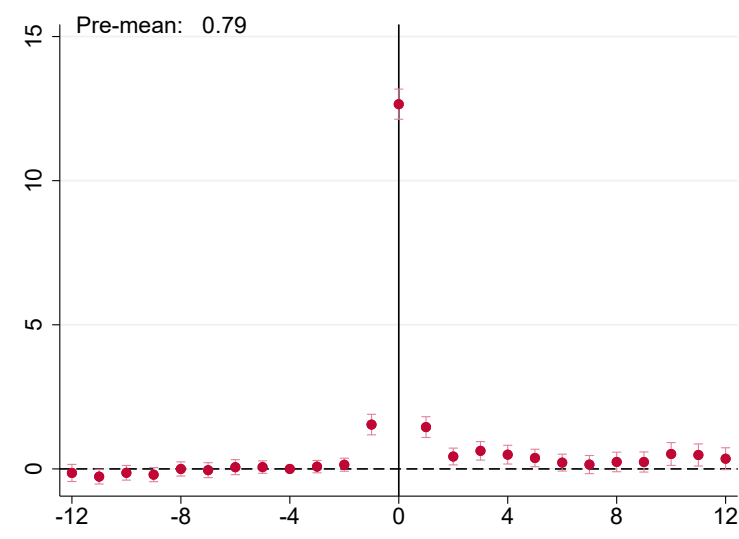

(a) Days in hospital

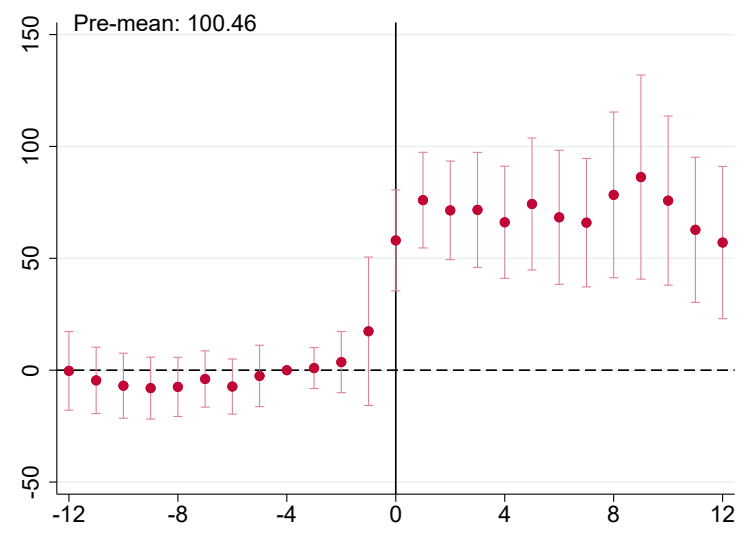

(c) Spendings on prescription drugs in Euro

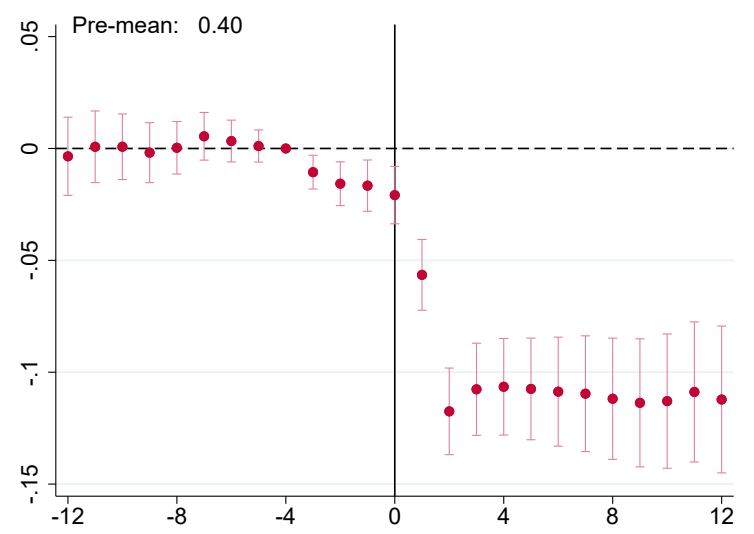

(e) Employment

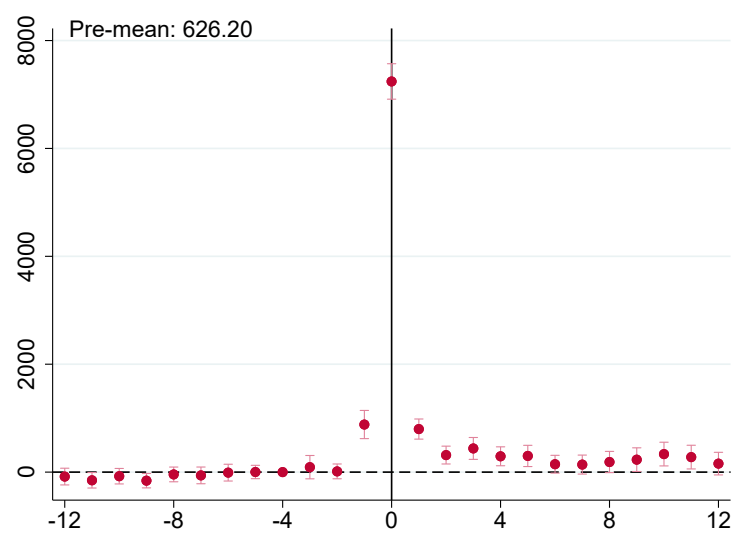

(b) Total health-care spendings in Euro

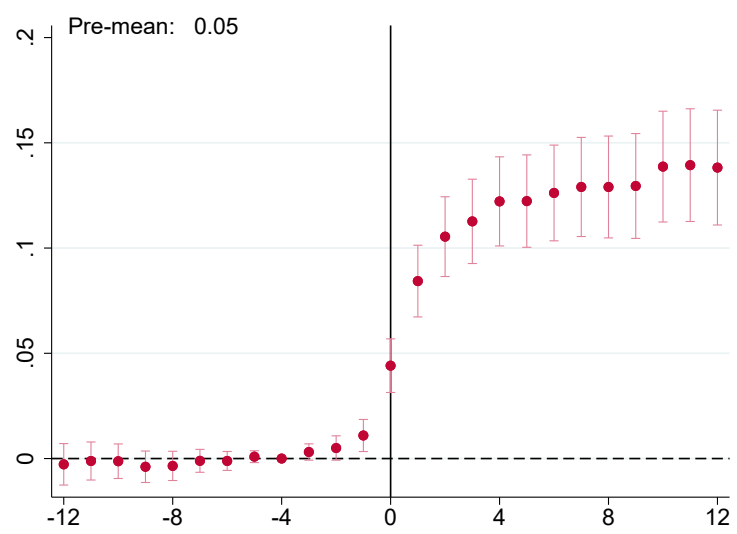

(d) Receipt of care allowance $(0 / 1)$

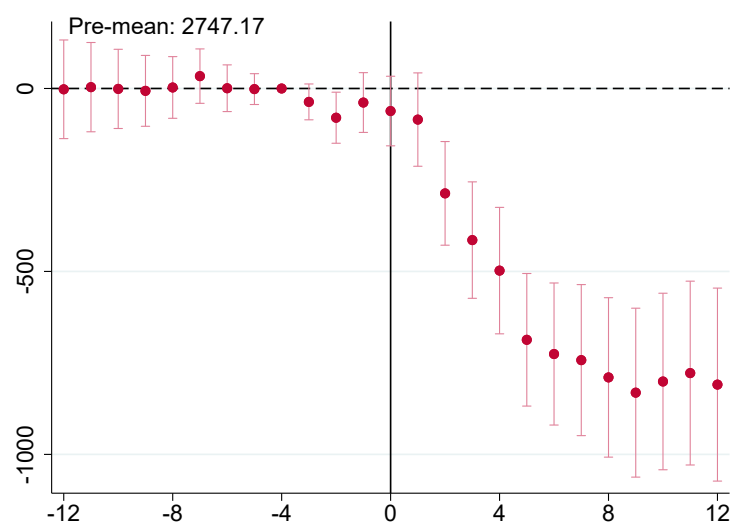

(f) Quarterly earnings in Euro

Notes: Each panel of the figure shows the event-study coefficients estimated from equation (1) and the corresponding 95 percent confidence intervals. They are based on the sample of parents who survive the entire time horizon of our analysis (survival $\geq 3$ years). Standard errors are clustered at the individual level. Pre-mean refers to the mean of the respective outcome variable four quarters prior to the parental stroke. 
Figure A.8: Families with surviving parents only: Impact of parental stroke on children's labor market outcomes

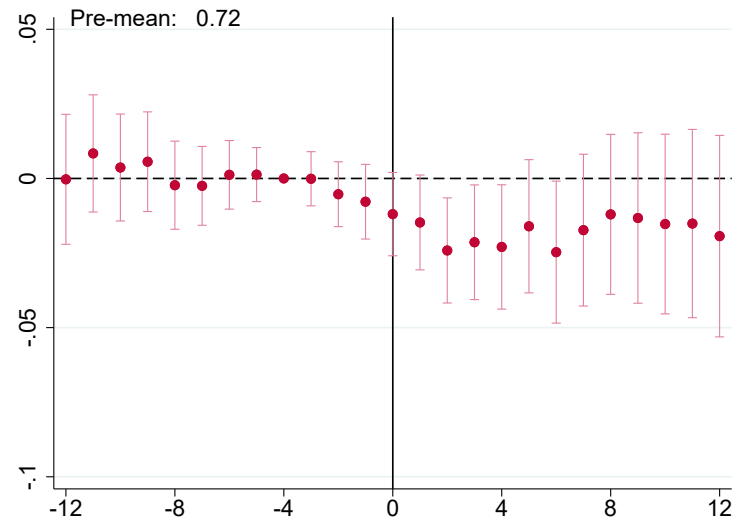

(a) Employment

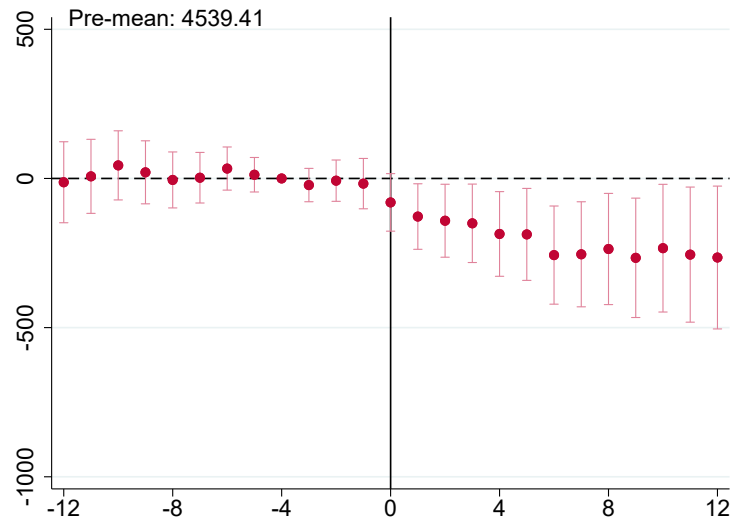

(b) Quarterly earnings in Euro

Notes: Each panel of the figure shows the event-study coefficients estimated from equation (1) and the corresponding 95 percent confidence intervals. They are based on the sample of children whose parents survive the entire time horizon of our analysis (survival $\geq 3$ years). Standard errors are clustered at the individual level. Pre-mean refers to the mean of the respective outcome variable four quarters prior to the parental stroke. 


\section{A.4 Additional results regarding the liberalization of foreign care workers in Austria}

\section{A.4.1 Salience of the reform}

To change behavior as a response to the increased availability of foreign care workers, Austrian families with caring responsibilities needed to be aware of the 2007 reform. One way to assess the salience of the reform is to examine its press coverage. Figure A.9 displays the number of press articles mentioning the phrase 24 Stunden Pflege (24h care work), an expression often used to describe the content of the reform in German.$^{2}$ We display the number of articles by quarter from January 2004 until December 2009, and for the major Austrian newspapers $3^{3}$ Figure A.9 shows a sharp increase in press articles about 24 Stunden Pflege exactly around the time when the new law was discussed in parliament. Furthermore, the coverage of the reform continued to be high in the following year when the new law was implemented. This suggests that the salience of the reform has been quite large, with many people knowing about the new possibilities regarding finding a (foreign) care worker.

Figure A.9: Press articles referring to the reform

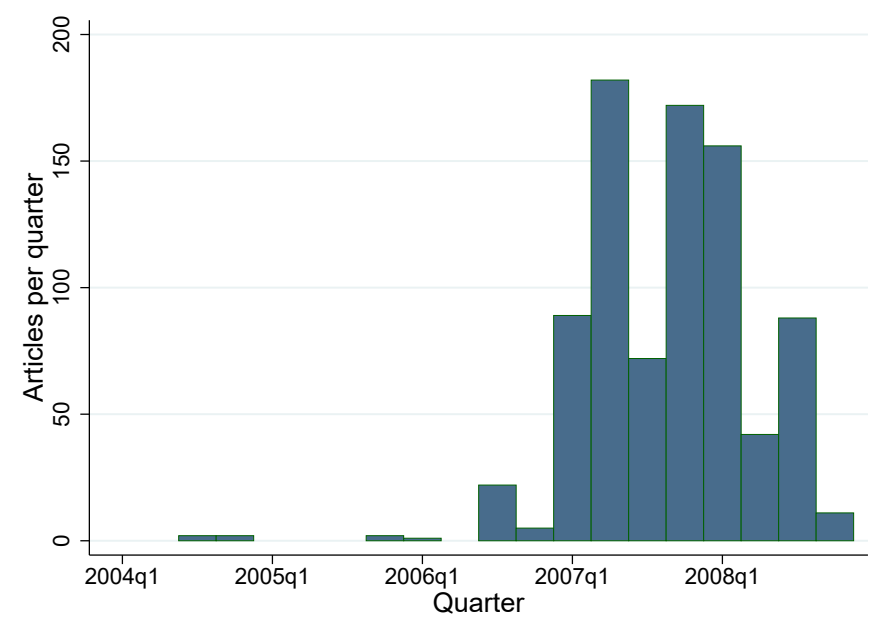

Notes: This figure shows the number of press articles mentioning 24h Pflege, an expression often used to describe the content of the 2007 reform. It displays the number of articles refering to the reform by quarter.

\footnotetext{
${ }^{2}$ Using other expressions associated with the reform give qualitatively similar results.

${ }^{3}$ We constructed the graph by scraping the newspaper archive AOMlibrary by the Austrian Press Agency (APA), which contains a full-text archive of most newspapers in Austria. The sample is restricted to large daily newspapers. This covers seven newspapers in total, including Kurier, Der Standard, Die Presse, and Krone.
} 


\section{A.4.2 Legalization}

Figure A.10: Number of female self-employed in Austria by quarter

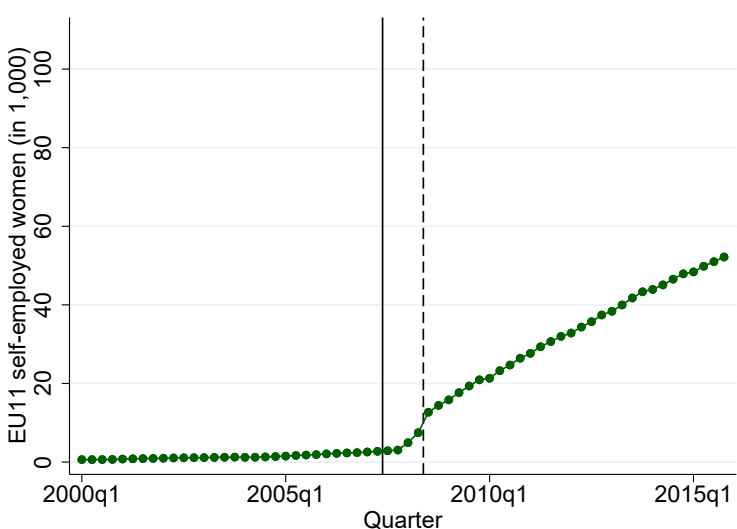

(a) EU11 self-employed women

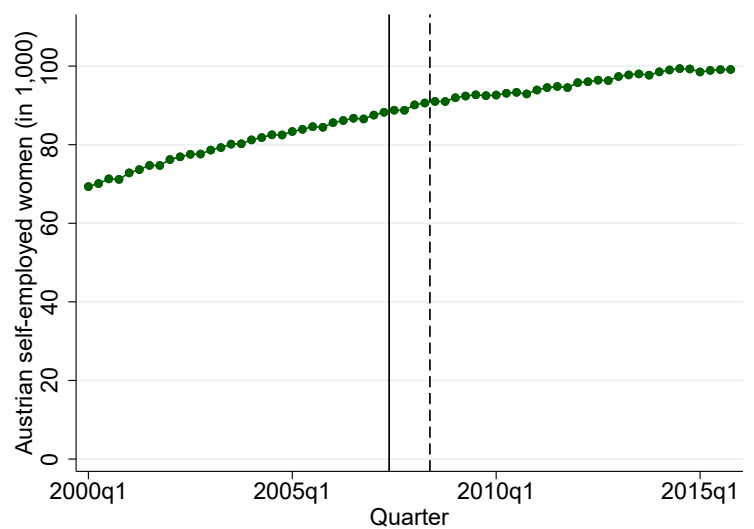

(b) Austrian self-employed women

Notes: The panels of this figure show the number of self-employed women in Austria for each quarter from 2000 to 2015. The panel to the left (to the right) refers to EU11 nationals (Austrians). The solid line highlights the quarter in which the home care work reform was implemented. The dashed line highlights the quarter until which amnesty was granted to illegal home care workers (Larsen et al. (2009)). Source: Austrian Social Security Data.

\section{A.4.3 Characteristics of EU11 self-employed in personal services in Austria}

Figure A.11: Characteristics of EU11 nationals employed in personal services

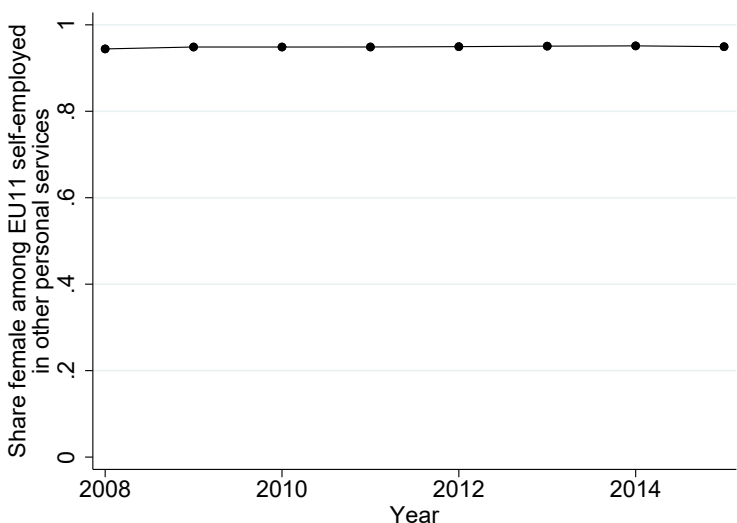

(a) Share female

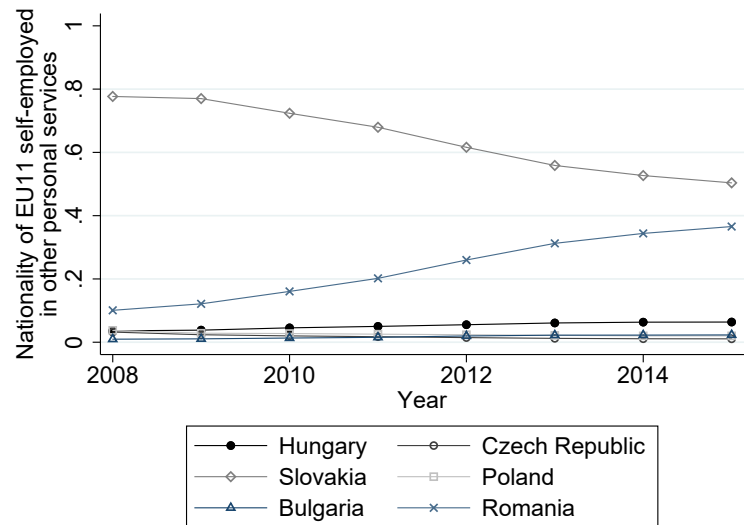

(b) Nationality

Notes: The panels of this figure show the characteristics of EU11 self-employed in personal services in Austria from 2008 to 2015. The panel to the right does not include those with a nationality from the Baltic States or from Slovenia because their shares are negligibly small (below 0.01 in all years). Source: BALI (budget, labour market and benefit receipt information) online database.

\section{A.4.4 Number of male care workers over time}


Figure A.12: Number of male care workers in Austria

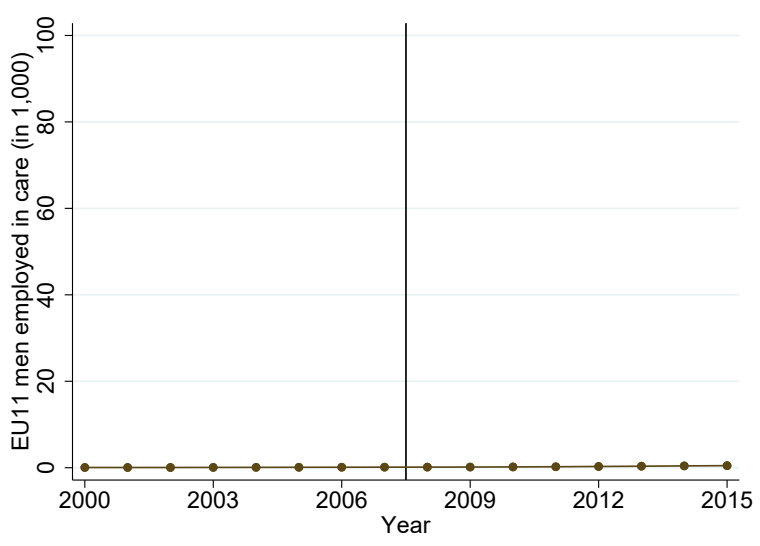

(a) EU11 men employed in care

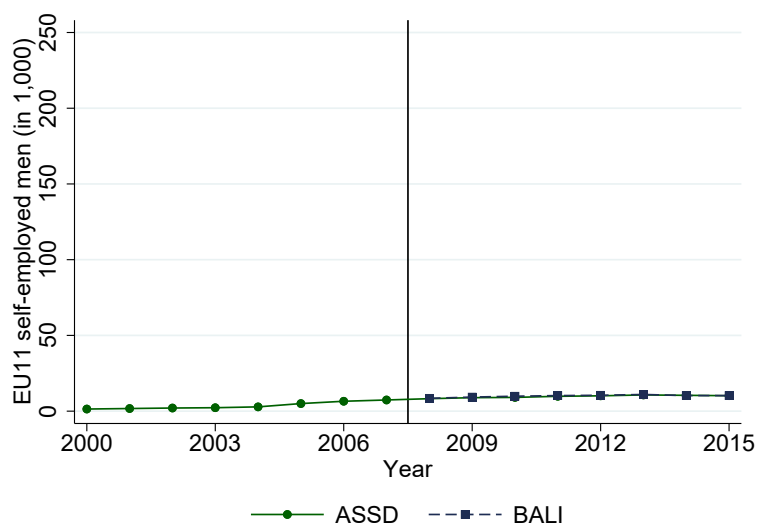

(c) EU11 self-employed men

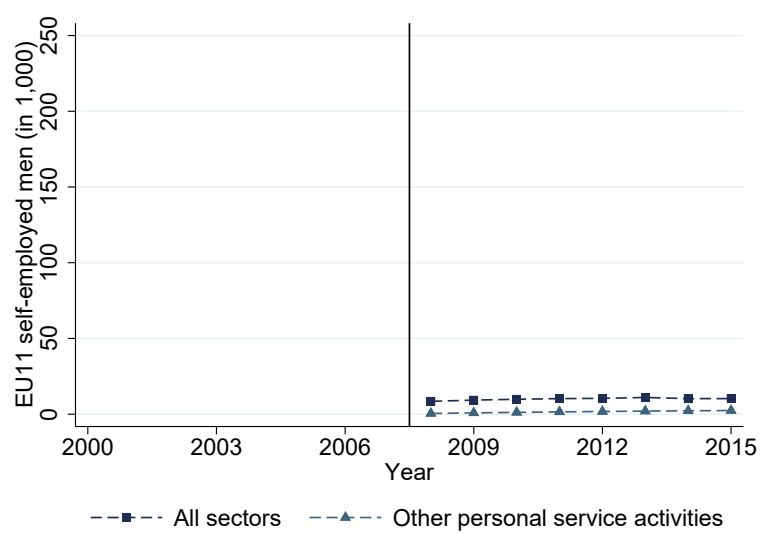

(e) EU11 self-employed men by sector

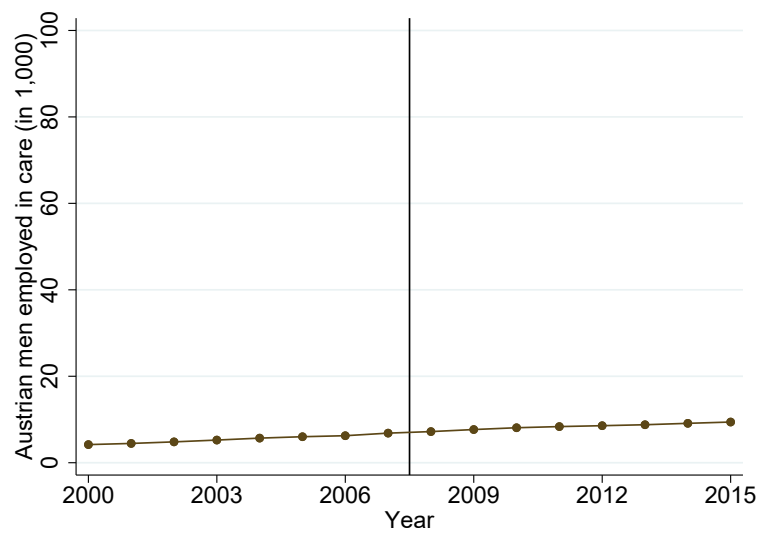

(b) Austrian men employed in care

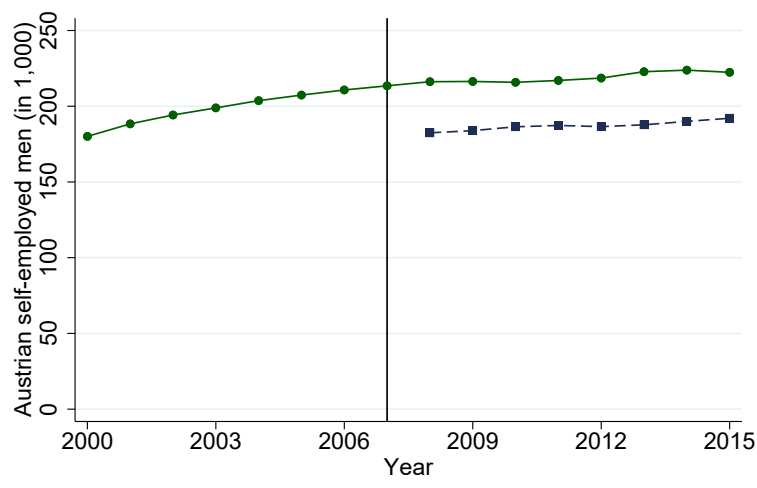

$\longrightarrow$ ASSD ----- BALI

(d) Austrian self-employed men

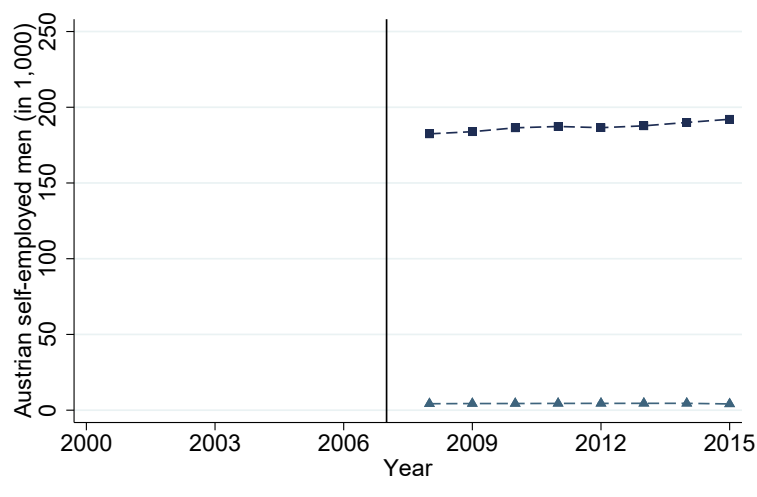

---- All sectors - - - - - Other personal service activities

(f) Austrian self-employed men by sector

Notes: Notes: The panels of this figure show the average number of male care workers in Austria from 2000 to 2015. For each year we take the average over the total number employed at four reference dates. The panels to the left (to the right) refer to EU11 nationals (Austrians). Panels a) and b) include all employees in the NACE categories with care activities. Panels c) and d) include all self-employed men from two different data sources. Panels e) and f) distinguish between all selfemployed men and those in "Other personal service activities" based on the BALI data. Source: Austrian Social Security Data, BALI (budget, labour market and benefit receipt information) online database. 